\title{
The Significance of Lunar Water Ice and Other Mineral Resources for Rocket Propellants and Human Settlement of the Moon
}

\author{
William A. Ambrose \\ Bureau of Economic Geology, John A. and Katherine G. Jackson School of Geosciences, University of \\ Texas at Austin, University Station, Box X, Austin, Texas, 78713, U.S.A. \\ (e-mail: william.ambrose@beg.utexas.edu)
}

\begin{abstract}
$\mathrm{F}$ uture success in exploration and human habitation of the solar system will depend on space missions and settlements becoming more self-sustaining through exploitation of extraterrestrial (i.e., local) energy and material resources. For example, the Moon contains a wide variety of energy minerals and other resources that can potentially be used for manufacture of propellants for space transportation, volatiles for manufacture of chemicals, and metals for construction of solar power facilities, industrial plants, and structures for human habitation. If water ice in polar regions on the Moon is proven to exist in large quantities, these resources could not only support human habitation but could also be used to manufacture rocket propellants, reducing dependency on Earth for these resources, thereby making human space exploration more economically viable. Moreover, the lower gravity well of the Moon could be used as a launching site for missions to Mars and other worlds in the solar system, given the possibility of water-ice and other lunar resources. New exploration tools will need to be developed to fully and accurately characterize the potential lunar resource base. For example, detection and quantification of suspected water-ice resource in lunar polar regions in recent missions involve an array of technologies not commonly used in hydrocarbon exploration on Earth, such as synthetic aperture radar, epithermal neutron detectors, and imaging of reflected ultraviolet starlight using Lyman-alpha scattering properties. Optimal locations for potential lunar bases and industrial facilities reflect several factors that include the distribution of water ice, volatiles (nitrogen), nuclear materials (helium-3, thorium, and uranium), and metals (titanium, magnesium, and iron). Other important factors are the duration of insolation (sunlight), where solar power facilities could be constructed in polar
\end{abstract}


areas with constant or near-constant illumination, as well as strategies that involve key orbital positions (Lagrangian points) to maximize fuel resources using less overall delta-v, defined as incremental change in spacecraft velocity to achieve a new orbital configuration.

\section{OBJECTIVES, DATA, AND METHODS}

The primary objective of this study is to review lunar resources that could be used for in-situ production of propellants and to support human missions and settlements, with an emphasis on hydrogen and water-ice resources. This chapter summarizes the presently known occurrence and distribution of hydrogen and water-ice resources on the Moon and discusses the impact of these and other resources such as metals and volatiles on possible areas for lunar bases and industrial facilities.

This chapter also characterizes the potential for human settlement in five regions on the Moon in terms of access to in-situ resources and strategic location for efficiently transferring material from mining sites to launch facilities involving minimal propellant consumption and lower delta-v costs. These regions are (1) polar, (2) nearside equatorial, (3) Oceanus Procellarum, (4) nearside limb, and (5) farside. These regions were selected on the basis of their location relative to suspected deposits of water ice and other types of strategic in-situ resources described in detail in the Lunar Resources section. These other resources include (1) hydrogen and oxygen occurring other than water ice; (2) helium-3; (3) uranium and thorium; (4) regolithrelated metals such as titanium, iron, and aluminum; (5) elements of pyroclastic origin that include iron, zinc, cadmium, mercury, lead, copper, and fluorine; (6), rare metals and platinum-group elements such as nickel, platinum, palladium, iridium, and gold that may occur within segregated impact melt sheets and layered mafic extrusives; and (7) volatiles such as nitrogen, carbon, and lithium that occur either with breccias or in exhalative deposits. In addition, these lunar regions were evaluated in terms of their potential for hosting lunar facilities, particularly the primary base of operations, that could be strategically located to efficiently transfer material from mining sites to launch facilities that would involve minimal propellant consumption and delta-v. Another important factor is the requirement for constant solar illumination for solar power facilities maximized in lunar polar areas. Data included in this chapter include results from a variety of recent missions pertinent to detection and characterization of hydrogen and water- ice resources on the Moon, including Clementine and Lunar Prospector, as well as preliminary and recent results from Kaguya, Chang'e 1, Chandrayaan-1, and the Lunar Reconnaissance Orbiter (LRO) missions.

\section{INTRODUCTION}

The Vision for Space Exploration, announced by President George W. Bush in a speech on January 14, 2004, is a commitment by the United States for a sustained human presence in space, beginning with settlement on the Moon and followed by expeditions to near-Earth asteroids and Mars. Although recent initiatives from President Barack Obama have canceled human lunar settlement missions, there may be an inevitable return to the Moon as a result of future changes in national space policy or developments driven by commercial interests in the Moon and energy resources beyond the low Earth orbit (LEO).

Space exploration has produced an array of benefits and technical advances in fields as diverse as agriculture, transportation, communications, cartography, medicine, weather forecasting, as well as navigation and geopositioning technology (Lewis, 1996; Gordon, 2004). For example, some of the early benefits from space technology were weather and communications satellites such as the Television Infrared Observation Satellite (TIROS) and Telstar, respectively, in the early 1960s (Clarke, 1968), whereas others, such as avionics, fuel cells, integrated electronic circuits, computers, and computer-controlled machining, were derived later from the Apollo, Skylab, and Space Shuttle programs. Other technological benefits from these space programs include advances in medicine and many fields of engineering, as well as statistical methods to evaluate the reliability of complex electronic and mechanical systems.

Future technological benefits are likely as a result of continued space exploration of other worlds. However, these potential benefits could be offset by the currently high lifting costs from Earth, which were up to US $\$ 10,000 / \mathrm{lb}$ (US $\$ 22,000 / \mathrm{kg}$ ) in 1996 dollars ( US $\$ 13,640 / \mathrm{lb}$ [ $\sim$ US $\$ 30,000 / \mathrm{kg}$ in 2009 dollars) of payload for the United States Space Shuttle system (Lewis, 1996). These lifting costs are estimated to be even higher ( US \$15,900/lb [ US \$35,000/kg]) in 2003 
dollars ( US $\$ 18,550 / \mathrm{lb}$ [ US $\$ 40,800 / \mathrm{kg}$ ] in 2009 dollars) for transportation of large payloads from the Earth to a geosynchronous orbit (GEO) (Duke et al., 2003). A long-term presence on other worlds such as the Moon, to be economically viable and sustainable, will require in-situ resource utilization of a variety of resources, including regolith (soil) materials for construction of a Moon base and solar power installations, particularly near the poles in areas of near-constant illumination and where suspected deposits of water ice exist (Bussey et al., 2005; Spudis, 2008); hydrogen and oxygen for manufacture of rocket propellants and water for human consumption (Lewis, 1996; Spudis, 1996); and helium-3 to supply energy not only for a Moon base but also as a source of energy for importation to Earth (Schmitt, 2006). Other resources such as metals and volatiles will be required and are summarized in Mendell (1985) and Heiken et al. (1991).

Historically, no United States space program involving human spaceflight, such as Apollo (1961-1975, including the Apollo-Soyuz mission) and the Space Shuttle (1981-2009, the time of this writing) has been economically self-sustaining, although long-term human habitability in space has been demonstrated with individual cosmonauts remaining on the Mir Space Station (launched in 1986) for periods of up to $1 \mathrm{yr}$ (Sheehan, 1992) as well as long-term stays by astronauts and cosmonauts on the International Space Station, scheduled for missions until at least 2017. Although the International Space Station, the most expensive structure ever built ( $~ € 100$ billion [European Space Agency, 2009]) has been in operation for more than $10 \mathrm{yr}$ and has been a platform for scientific investigations, particularly in space biology and physics, it has not achieved a level of self-sufficiency and routinely requires delivery of resources from space shuttle and Soyuz flights from Earth to be maintained.

Moreover, the Space Shuttle program, although originally envisaged to be cost-effective through recovery and reuse of solid rocket boosters, as well as by redeployment of the same space vehicle for multiple flights, has proved to be expensive, costing an estimated US \$174 billion, or approximately US \$450 million/flight in 1992 dollars, or US \$266 billion ( US \$688 million/flight) in 2009 dollars, during its approximately 30-year history (Pielke and Byerly, 1992). These expenses, resulting primarily from having to remove and refurbish the engines and to replace external tiles after every mission, both labor-intensive repair operations, contribute to overall high payload costs. However, despite its high mission costs, the Space Shuttle program achieved a measure of success in delivering large payloads (having a payload capability of up to $\sim 27$ short tons $[\sim 24,550 \mathrm{~kg}]$ to LEO) for construction of the International Space Station, as well as serving as a platform for launching, deploying, and repairing satellites, with the Hubble Space Telescope as a well-known example.

Interplanetary spaceflight and settlement of other planets, beginning with the Moon and Mars, are expected to incur long-term expenses. For example, the Constellation program, which had the goal of returning to the Moon with the goal of establishing and maintaining human settlements, had been estimated to cost at least US $\$ 150$ billion from 2008 to 2020, the former projected date for the first manned landing in the return to the Moon (National Aeronautics and Space Administration, 2009a). Estimates vary concerning the cost to send humans to Mars, but most projected costs are in excess of US $\$ 1$ trillion, and the technical difficulties of manned space missions to Mars, including resources and in-flight safety factors for human survival during spaceflight to Mars, have yet to be resolved.

\section{ROCKET PROPELLANTS}

Most current space transportation systems, with the exception of the Deep Space 1 technology demonstration spacecraft (Kerslake et al., 2000) and the SMART-1 mission that used solar electric propulsion to go from Earth to the Moon in 10 months (Foing, 2007), depend on chemical propellants, which are composed of two components: fuels and oxidizers. Fuels and oxidizers are represented by a wide variety of chemicals, with the elements hydrogen and oxygen being common constituents (Tables 1,2). Fuels, when burned in the presence of oxygen, provide propulsion for rocket systems. Oxidizers are agents that release oxygen to combine with fuels (Braeunig, 2008). Potential nonchemical propulsion systems also include nuclear fuels such as helium-3 (Schmitt, 2006, 2013) and uranium (Campbell et al., 2013), and other materials such as xenon for ion rockets (Monterde et al., 1997; Patterson et al., 2002). Common liquid chemical fuels for rocket propellants include kerosene $\left(\mathrm{C}_{12} \mathrm{H}_{26}\right)$, liquid hydrogen $\left(\mathrm{H}_{2}\right)$, methane $\left(\mathrm{CH}_{4}\right)$, and hydrazine $\left(\mathrm{N}_{2} \mathrm{H}_{4}\right)$ (Table 1$)$. The simple single-stage rocket launched by Robert Goddard in 1926 used gasoline fuel with liquid oxygen as an oxidizer (National Aeronautics and Space Administration, 2003). In contrast, the Saturn V rocket from the Apollo program was a three-stage system using kerosene (RP-1) and 
Table 1. Summary of common chemical fuels for rocket propellants.*

\begin{tabular}{|c|c|c|c|c|}
\hline Fuel & Hydrogen $\left(\mathrm{H}_{2}\right)$ & Methane $\left(\mathrm{CH}_{4}\right)$ & $\begin{array}{l}\text { Hydrazine } \\
\left(\mathrm{N}_{2} \mathrm{H}_{4}\right)\end{array}$ & $\begin{array}{c}\text { n-Dodecane } \\
\text { (kerosene) }\end{array}$ \\
\hline $\begin{array}{l}\text { Specific impulse, } \\
\text { with liquid } \\
\text { oxygen at } \\
\text { sea level (s) }\end{array}$ & 381 & 299 & 303 & 289 \\
\hline Boiling point $\left({ }^{\circ} \mathrm{C}\right)$ & -252.9 & -161.6 & 113.5 & 216.3 \\
\hline $\begin{array}{l}\text { Storage, safety, } \\
\text { and cost factors }\end{array}$ & $\begin{array}{l}\text { Requires cold storage; } \\
\text { occupies large volumes } \\
\text { relative to denser fuels; } \\
\text { expensive to produce }\end{array}$ & $\begin{array}{l}\text { Relatively inexpensive; } \\
\text { clean burning with LOX } \\
\text { and nontoxic; requires } \\
\text { less storage than liquid } \\
\text { hydrogen }\end{array}$ & $\begin{array}{l}\text { Caustic but does not } \\
\text { require cold storage }\end{array}$ & $\begin{array}{l}\text { Does not require cold } \\
\text { storage; less expensive } \\
\text { and denser than liquid } \\
\text { hydrogen }\end{array}$ \\
\hline $\begin{array}{l}\text { Historical and } \\
\text { current use }\end{array}$ & $\begin{array}{l}\text { Apollo (middle and } \\
\text { upper stages), space } \\
\text { shuttle (external tank) }\end{array}$ & No flight history & $\begin{array}{l}\text { Original use for jet } \\
\text { propulsion; common } \\
\text { in space probes }\end{array}$ & $\begin{array}{l}\text { Apollo: Saturn first } \\
\text { stage }\end{array}$ \\
\hline $\begin{array}{l}\text { Natural occurrence } \\
\text { on the Moon }\end{array}$ & $\begin{array}{l}20-200 \mathrm{ppm} \text { in regolith; } \\
\text { possibly } 2 \mathrm{wt} . \% \text { in } \\
\text { polar regions }\end{array}$ & None detectable & None & None \\
\hline
\end{tabular}

*Data from Lucey et al. (1995), Feldman et al. (2000), Johnson et al. (2001), and Braeunig (2008).

liquid hydrogen fuels. The first stage (S-IC) contained five F-1 engines that provided 7.5 million pounds ( $\sim 3.4$ million kilograms) of thrust using kerosene. The S-II second stage used five J-2 engines, burning liquid hydrogen to achieve a velocity of more than $15,000 \mathrm{mi} /$ $\mathrm{hr}(>6.8 \mathrm{~km} / \mathrm{s})$ and an altitude of approximately $115 \mathrm{mi}$ $(185 \mathrm{~km})$. The S-IVB third stage, fueled by liquid hydrogen, was then ignited to place the spacecraft into Earth's orbit, followed by restarting its J-2 engine to make the translunar injection burn (National Aeronautics and Space Administration, 2009b). Liquid hydrogen is also used as a fuel for the space shuttle, with most of the fuel stored in an external tank jettisoned before attaining LEO.

These major types of rocket fuels vary in specific impulse or thrust (Table 1). Specific impulse is defined as how many pounds or kilograms of thrust are attained from consuming $1 \mathrm{lb}$ (or $\mathrm{kg}$ ) of propellant per second (Braeunig, 2008). Fuel density is also an important attribute, which impacts storage volume and time required to achieve orbit. For example, although liquid hydrogen provides a greater impulse (30-40\%) than other chemical rocket fuels such as methane, its low density means that it occupies approximately seven times more volume per unit mass than dense fuels such as kerosene. Moreover, liquid hydrogen is an expensive fuel to produce and store compared with other types of liquid propellants (Lewis, 1996). However, dense-fueled launch vehicles require higher takeoff thrust, although this higher thrust also means that such vehicles can potentially reach orbit earlier.

Chemical rocket fuels also differ in terms of storage safety and expense. Hydrazine, first used as a jet fuel by Germany toward the end of the Second World War, is a common rocket fuel and is typically used as a propellant for many unmanned probes as, for example, the Giotto mission to Halley's Comet (Whipple, 1985). Although it can be stored for long periods, hydrazine is highly toxic and caustic. Hydrazine is an example of a hypergolic fuel, which ignites spontaneously with oxidizers, requiring no ignition source (Braeunig, 2008). Methane, although providing less thrust than liquid hydrogen, requires less storage space because it is a denser fuel (Table 1). It is also typically the most common component of natural gas and is therefore less expensive to produce than liquid hydrogen.

Commonly used oxidizers for combustion of rocket fuel include liquid oxygen $\left(\mathrm{O}_{2}\right.$, also termed LOX), ammonium perchlorate $\left(\mathrm{NH}_{4} \mathrm{ClO}_{4}\right)$, nitrogen tetroxide $\left(\mathrm{N}_{2} \mathrm{O}_{4}\right)$, hydrogen peroxide $\left(\mathrm{H}_{2} \mathrm{O}_{2}\right)$, and nitrous oxide $\left(\mathrm{N}_{2} \mathrm{O}\right)$ (Table 2 ). As with fuels, oxidizers vary in terms of storage attributes and effectiveness. Many are difficult to store and handle because of toxicity or being cryogenic. Although liquid oxygen provides a relatively high impulse, it requires cold storage. Nitrogen tetroxide can be stored for long periods, but it is toxic. Hydrogen peroxide is nontoxic but provides a lower impulse than other oxidizers. Nitrogen tetroxide and hydrazine fuel are used in military, orbital, 
and deep space rockets because both liquids can be stored for long periods under conventional temperatures and pressures. Nitrous oxide, commonly used in amateur rocketry, decomposes exothermically into nitrogen and oxygen and gives a specific impulse of $170 \mathrm{~s}$ (Table 2). Liquid oxygen has been used as an oxidizer in many United States space missions as well as early 20th-century rockets. In the mid-1960s, the Centaur and Saturn upper stages both used liquid oxygen. The main engines of the space shuttle also use liquid oxygen, as well as Delta IV and H2A rockets.

Solid propellants are used for solid-fuel rockets as, for example, the two external solid-fuel boosters on the space shuttle. Examples of solid propellants include aluminum powder (fuel) mixed with ammonium perchlorate powder $\left(\mathrm{NH}_{4} \mathrm{ClO}_{4}\right)$, an oxidizer, held together with a base of rubberlike fuels known as PBAN (polybutadiene/acrylic acid/acrylonitrile) and HTPB (hydroxyl-terminated polybutadiene). Solidfuel rockets are easier to store and handle than liquidfuel rockets, which makes them ideal for military use as, for example, the Trident II D5 ballistic missile. However, unlike liquid-fuel engines that can be throttled, stopped, or restarted, solid-fuel rockets cannot be switched off, and once ignited burn to completion because the fuel and the oxidizer are mixed together. Another disadvantage of solid-fuel rockets is that they have a lower specific impulse than that of liquid-fuel rockets (Lewis, 1996).

\section{MANNED LUNAR MISSIONS AND RETURN TO THE MOON}

\section{Apollo and Constellation Programs}

The principal objective of the Apollo program, which nominally included the Mercury, Gemini, and Apollo missions from 1961 to 1972, was not to primarily generate economic and technological benefits, but instead to defeat the former Soviet Union in a space race by landing Americans on the Moon and safely returning them to Earth before 1970. Apollo's secondary scientific objectives were to gather data on the Moon to address questions concerning the age and formation of the Moon (Wilhelms and McCauley, 1971; Wasserburg et al., 1972; Heiken et al., 1991), chronostratigraphy (Wilhelms, 1987), emplacement of near-surface igneous deposits (Howard et al., 1972), petrology and petrography (Marvin, 1973; Short, 1975; Papike et al., 1998), crustal composition, geochemistry, characterization of compositional asymmetry (Wasson and Warren, 1980; Haines and Metzger, 1980), subsequently refined by Jolliff et al. (2000) from the 
Clementine and Lunar Prospector missions, characterization of the regolith (Marvin et al., 1971), and interior structure from seismic instrumentation deployed on the lunar surface (Latham et al., 1970). From 1959 to 1973, the National Aeronautics and Space Administration (NASA) spent US $\$ 23.6$ billion on manned spaced flight, exclusive of infrastructure and support, of which approximately US $\$ 20$ billion ( US $\$ 150$ billion in 1992 dollars and US \$228 billion in 2009 dollars) was for Apollo (National Aeronautics and Space Administration, 2009c). Apollo used virtually no lunar resources for economic return and technical support for the program, except providing approximately $850 \mathrm{lb}(\sim 382 \mathrm{~kg})$ of rock samples for mineralogical, chemical, and isotopic analysis, as well as later identification and quantification of helium-3, a potential energy resource (Schmitt, 2006). All fuel and material resources for the Apollo missions to the Moon were produced and transported from Earth, and human activity on the Moon was limited to data-gathering traverses in periods ranging from only approximately $2.5 \mathrm{hr}$ during a $21 \mathrm{hr}$ stay on the lunar surface (Apollo 11) to multiple traverses during a $75 \mathrm{hr}$ stay (Apollo 17). Other activities included setting up instrumentation for experiments and gathering data such as soil mechanics, solar-wind properties, dust detection, surface electrical properties, cosmic ray detection, atmospheric properties, and internal heat flow and seismicity (Short, 1975).

The Constellation program, canceled in 2010 by President Obama, was designed to return astronauts to the Moon by 2020. In contrast to project Apollo, the return to the Moon was envisioned to involve longterm human settlement as well as in-situ development of mineral and energy resources to support life and for manufacture of rocket propellants (Seedhouse, 2009). The Ares I launch vehicle was designed similar to the Apollo rocket design, using a J-2X engine. The Ares V cargo vehicle had a payload capacity of more than $280,000 \mathrm{lb}$ (>127,300 kg) for LEO. The Earth-departure stage was to use a combination of liquid hydrogen and liquid oxygen for translunar orbital insertion (National Aeronautics and Space Administration, 2009a). The main spacecraft component (Orion) was to be launched separately to link up with the Altair lunar lander in LEO. Like Apollo, a lunar orbit rendezvous mission would have been flown. However, the Altair would have been launched separately on the Ares V rocket. Orion would remain unmanned in lunar orbit, with the entire crew landing on the lunar surface. Preliminary landing targets were to include possible lunar polar regions as well as equatorial sites that were vis- ited by Apollo, although specific landing sites were undecided.

\section{Lunar Resources}

\section{Significance}

Verification that water-ice resources exist in great quantities on the Moon will increase the long-term economic viability of a return to the Moon. Although initial lunar missions will involve large investments of capital, as more and more lunar-base propellants are brought into service, obviating the need for Earthmanufactured propellants, the lunar base will begin to contribute to paying for overall transportation costs through manufacture of in-situ propellants that can be used for rockets launched from the Moon's lowgravity well (Duke et al., 2003, 2006). For example, hydrogen and oxygen, mined on the Moon for rocket fuel and oxidizer, respectively, could be transported to a refueling space station in either LEO or low lunar orbit (LLO). After many cycles, the cumulative mass of material delivered to the refueling space station would be larger than the mass originally launched from Earth. Other in-situ lunar resources such as volatiles, occurring both at the lunar poles and in the regolith, as well as metals, will increase the viability of a longterm human presence on the Moon, further reducing payload requirements such as construction materials and other resources necessary for energy production.

\section{General Resource Base}

The Moon contains a wide variety of materials that can potentially be used for power generation, manufacture of rocket propellants, and construction of settlements and facilities (Table 3). Successful and economic development of these lunar resources will involve several factors that include energy costs in constructing mining infrastructure, extraction of ores (Bunch et al., 1979), and refining and concentrating resources as, for example, heating the regolith to $700^{\circ} \mathrm{C}\left(1292^{\circ} \mathrm{F}\right)$ to obtain hydrogen and helium-3 (Spudis, 1996; Schmitt, 2006). In addition, time and effort will need to be expended in characterizing, mapping, and selectively targeting areas where resources are concentrated. For example, optimizing the production of ilmenite $\left(\mathrm{FeTiO}_{3}\right)$ will involve identifying areas of relatively high concentrations of titaniumrich regolith such as those in Mare Tranquillitatis that were sampled by the Apollo 11 mission (O'Hara et al., 1974). Detailed mapping of areally restricted pyroclastic volcanic vent deposits will be required to characterize potential resources of a suite of volcanogenic 
Table 3. Summary of selected lunar resources.

\begin{tabular}{|c|c|c|c|}
\hline Resource & Use & Occurrence & References \\
\hline Helium-3 & $\begin{array}{l}\text { Nuclear power generation, } \\
\text { rocket propulsion }\end{array}$ & Ti-rich basalts up to $20 \mathrm{ppb}$ & Schmitt (2006) \\
\hline $\begin{array}{l}\text { Uranium/thorium, rare-earth } \\
\text { elements }\end{array}$ & $\begin{array}{l}\text { Nuclear power generation, } \\
\text { rocket propulsion }\end{array}$ & $\begin{array}{l}\text { KREEP-rich basalts in Oceanus } \\
\text { Procellarum }\end{array}$ & Jolliff et al. (2000), Schultz et al. (2006) \\
\hline $\begin{array}{l}\text { Pyroclastic-related Fe, Zn, } \\
\mathrm{Cd}, \mathrm{Hg}, \mathrm{Pb}, \mathrm{Cu}, \mathrm{F}\end{array}$ & $\begin{array}{l}\text { Electronics, chemicals, } \\
\text { special alloys }\end{array}$ & $\begin{array}{l}\text { Pyroclastic deposits and vents } \\
\text { in maria }\end{array}$ & Taylor and Martel (2003), Schultz et al. (2006) \\
\hline Nitrogen and carbon & Plastics and food & Breccias and volatile deposits & $\begin{array}{l}\text { Kaplan and Smith (1970), Abell et al. (1971), } \\
\text { Pillinger and Eglinton (1977), Mathew and } \\
\text { Marti (2000) }\end{array}$ \\
\hline $\begin{array}{l}\text { Metals/bulk regolith, } \\
\text { including iron, titanium, } \\
\text { and aluminum }\end{array}$ & Construction material, ores & $\begin{array}{l}\text { Fe and Ti in mare-fill basalts; } \\
\text { Al common throughout } \\
\text { the Moon }\end{array}$ & $\begin{array}{l}\text { Pieters (1978), Solomon and Head (1979), } \\
\text { Jolliff et al. (2000) }\end{array}$ \\
\hline $\begin{array}{l}\text { Precious metals, including } \\
\mathrm{Ni}, \mathrm{Pt}, \mathrm{Pd}, \mathrm{Ir}, \mathrm{Au}\end{array}$ & Electronics, special alloys & $\begin{array}{l}\text { Meteoritic debris in regolith, } \\
\text { regolith breccias, segregated } \\
\text { impact melt sheets, layered } \\
\text { mafic extrusives }\end{array}$ & $\begin{array}{l}\text { Pieters (1978), Solomon and Head (1979), } \\
\text { Jolliff et al. (2000), Taylor and Martel (2003), } \\
\text { O'Hara (2000), Schmitt (2008) }\end{array}$ \\
\hline Hydrogen & $\begin{array}{l}\text { Rocket propulsion, water } \\
\text { for human consumption }\end{array}$ & $\begin{array}{l}\text { Solar-wind } \mathrm{H} \text { in regolith } \\
(<100 \mathrm{ppm}) ; \text { also in } \\
\text { polar regions }\end{array}$ & Feldman et al. (1998, 2000), Gillis-Davis (2008) \\
\hline Oxygen & $\begin{array}{l}\text { Rocket propulsion, water } \\
\text { and air for human consumption }\end{array}$ & $\begin{array}{l}\text { Common in silicates } \\
(\sim 45 \% \text { wt. } \%) \text {; also in } \\
\text { polar ice deposits }\end{array}$ & Heiken et al. (1991), Feldman et al. (1998) \\
\hline
\end{tabular}


(A)

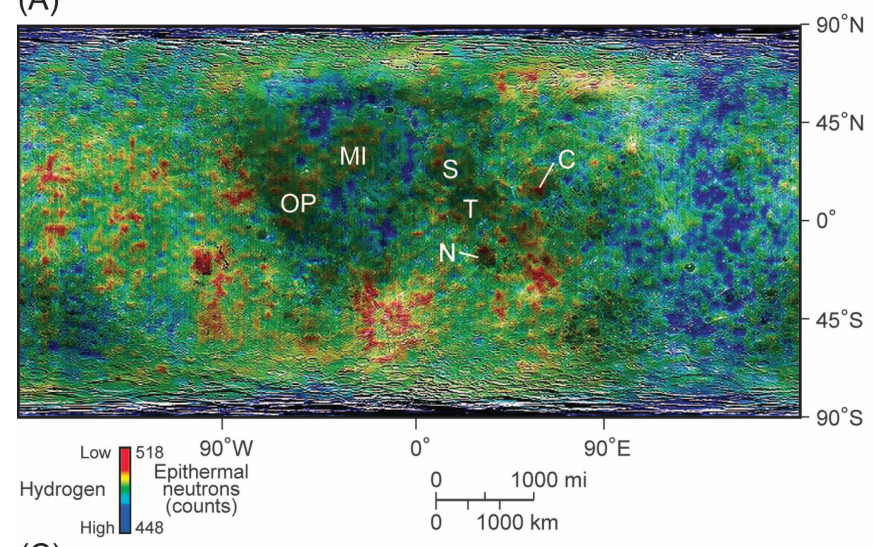

(C)

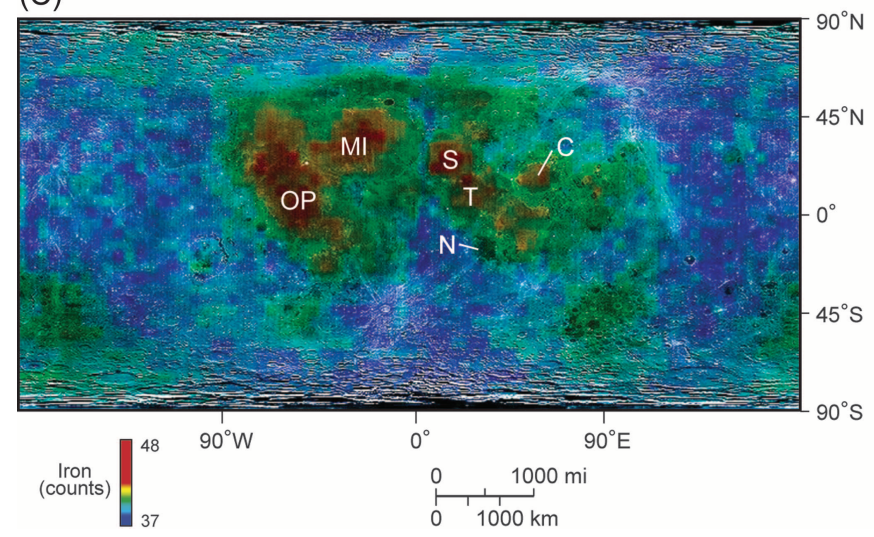

(B)

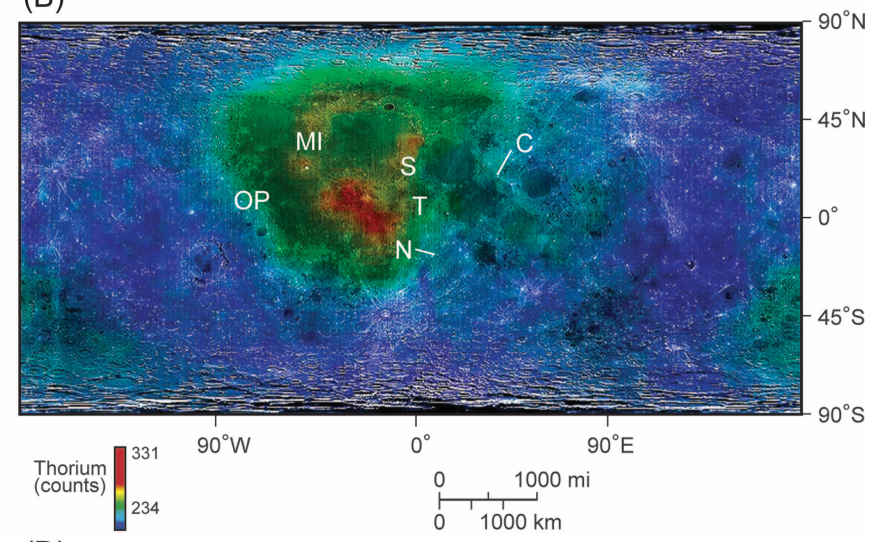

(D)

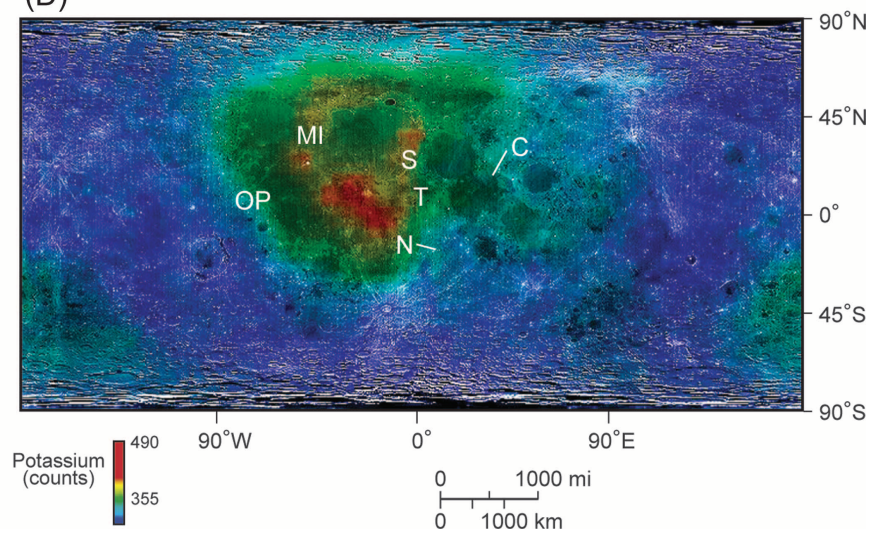

FIGURE 1. Global elemental abundance maps from the Lunar Prospector mission. (A) Hydrogen, with dark-green color coinciding with $60 \mathrm{ppm}$ or greater. (B) Thorium. Red corresponds to $9 \mathrm{ppm}$ or greater, and dark blue corresponds to less than $3 \mathrm{ppm}$. (C) Iron, expressed as FeO. Dark brown generally corresponds to $14 \mathrm{wt}$. \% or greater, and dark blue corresponds to $6 \mathrm{wt}$. \%. (D) Potassium. Red corresponds to $3000 \mathrm{ppm}$ or greater, and blue corresponds to less than 1000 ppm. Basins and areas: $\mathrm{C}=$ Mare Crisium; $\mathrm{MI}=$ Mare Imbrium; $\mathrm{N}=$ Mare Nectaris; $\mathrm{OP}=$ Oceanus Procellarum; $S=$ Mare Serenitatis; T = Mare Tranquillitatis. Sources: Lucey et al. (1995), Johnson et al. (2001), Gillis et al. (2004), and Gasnault et al. (2008).

elements that include iron, zinc, cadmium, mercury, lead, copper, and fluorine. Rare metals and platinumgroup elements may also reside in low concentrations in regolith breccias, highland impact breccias, segregated impact melt sheets (Solomon and Head, 1979; Taylor and Martel, 2003), as well as in possible layered mafic intrusives (O'Hara, 2000; Schmitt, 2008).

Hydrogen (Figure 1A) occurs over most of the Moon in the regolith in very low abundance (typically $<100 \mathrm{ppm}$ ) (Haskin and Warren, 1991) from implantation from the solar wind, a source for water for human consumption and rocket propellants. Recent results from spectroscopic studies also suggest the widespread occurrence of hydrated lunar materials (Clark, 2009; Pieters et al., 2009; Sunshine et al., 2009). Thorium (Figure 1B), helium-3, and uranium are sources for power generation and rocket propulsion (Schmitt, 2006, 2013; Campbell et al., 2013).
Thorium is relatively abundant in the southern part of Oceanus Procellarum (Figure 1B), where it is associated with late-stage melts rich in KREEP (potassium/ rare-earth elements [REEs]/phosphorus) constituents (Lawrence et al., 1998; Jolliff et al., 2000; Gasnault et al., 2008). Although thorium and uranium are present only as trace elements in most lunar rocks, even in those with abundant KREEP constituents, they may be most concentrated in regolith developed on the slopes and at the base of rhyolitic domes such as Mons Gruithuisen in northwest Mare Imbrium and in pyroclastic deposits in Rima Bode superimposed on highlands between Sinus Aestuum and Mare Vaporum (Hagerty et al., 2009). Oxygen, a volumetrically important constituent of silicate minerals, is approximately $45 \%$ of the lunar soil by mass (Heiken et al., 1991). The Moon also contains volatiles such as nitrogen and carbon, the building blocks of plastics and foodstuffs that will be vital to sustain life on the Moon, in 
very low levels of concentration (commonly $<2$ and $<10 \mathrm{ppm}$, respectively) that are bound in breccias, the regolith, and possibly in recent volatile deposits (Kaplan and Smith, 1970; Abell et al., 1971; Pillinger and Eglinton, 1977; Mathew and Marti, 2000). Volatiles, including water, also occur in lunar pyroclastic glasses (Saal et al., 2008).

Recent analysis of crater-penetration data suggests that mare-fill units (and therefore potential related metal resources) are thicker in Mare Imbrium than previously inferred (Thomson et al., 2009). The bulk regolith also has a variety of metals, principally iron (Figure 1C), titanium, and aluminum. High values of titanium concentration $\left(\mathrm{TiO}_{2}\right.$ content $1-11$ wt. \%) occur in young (2.7-3.6 b.y.) mare-fill units in Oceanus Procellarum (Pieters, 1978; Whitford-Stark and Head, 1980; Elphic et al., 1998). In addition, high concentrations of titanium ( $>6 \mathrm{wt}$. $\% \mathrm{TiO}_{2}$ ) occur in the basalts in Mare Tranquillitatis that are 3.4-3.8 b.y. old (Hiesinger et al., 1998). Other areas with great titanium abundances include basalts in southeastern Mare Serenitatis and western Oceanus Procellarum (Gillis et al., 2003).

Aluminum is ubiquitous on the Moon, being a common component of silicates in breccias and basalts. In addition, many lunar basalts are rich in iron, with some having $\mathrm{FeO}$ abundances between 17 and 22 wt. \% (Papike et al., 1998). Examples include FeOrich basalts in Mare Serenitatis (Davis, 1980), Oceanus Procellarum (Whitford-Stark and Head, 1980; Lucey et al., 1995), and Mare Imbrium (Bugiolacchi and Guest, 2008). Potassium, associated with REEs and phosphorus, occurs in late-stage intrusive melts in Oceanus Procellarum and isolated areas in Mare Imbrium (Figure 1D). Although $\mathrm{K}_{2} \mathrm{O}$ concentration in KREEP-rich materials is commonly only 1 to $2 \mathrm{wt}$. $\%$, the $\mathrm{K}_{2} \mathrm{O}$ content in granitic materials, which may be concentrated in silicic domes, may be as great as 5 to 8 wt. \% (Glotch et al., 2010). Other REEs, as well as thorium and uranium, are hosted by the phosphate whitlockite ([Ca $\left.\left.9 \mathrm{MgFe}\}\left\{\mathrm{PO}_{4}\right\}\right]_{6}\left[\mathrm{PO}_{3} \mathrm{OH}\right]\right)$, zircon, and rare accessories such as tungsten-bearing yttrobetafite $\left(\left[\mathrm{Ca}_{0.61}, \mathrm{Y}_{0.42}, \mathrm{REE}_{0.32}, \mathrm{Fe}_{0.25}, \mathrm{~Pb}_{0.18}, \mathrm{Th}_{0.12}, \mathrm{U}_{0.07}\right.\right.$, $\left.\mathrm{La}_{0.02}, \mathrm{Mn}_{0.01}\right]\left[\mathrm{Ti}_{1.24}, \mathrm{Nb}_{0.58}, \mathrm{~F}_{0.14}, \mathrm{Ta}_{0.02}, \mathrm{Zr}_{0.01}\right.$, $\left.\left.\mathrm{W}_{0.01}\right]\left[\mathrm{O}_{6.80}\right]\right)$, zirkelite $\left.\left([\mathrm{Ca}, \mathrm{Th}, \mathrm{Ce}][\mathrm{Zr}][\mathrm{Zr}, \mathrm{Ti})_{2}\right]\left[\mathrm{O}_{7}\right]\right)$, and zirconolite $\left(\mathrm{CaZrTi}_{2} \mathrm{O}_{7}\right)$ (Meyer and Yang, 1988; Ionov et al., 2006; Mokhov et al., 2008).

\section{Hydrogen and Water Ice}

Hydrogen, instead of oxygen, is the primary indicator of lunar water ice because of oxygen being abundant throughout the Moon, occurring in silicate and oxide minerals and glasses in all lunar materials. In contrast, lunar hydrogen occurs in the lunar soil (regolith) in small concentrations, ranging from 20 to slightly more than 100 ppm (Figure 1A). The Lunar Prospector hydrogen-abundance map indicates that in nearside mare basins, hydrogen levels are highest in Oceanus Procellarum and Mare Imbrium, although an extensive area exists in western Mare Imbrium, where hydrogen-abundance levels are comparable to those in the Maria Serenitatis, Tranquillitatis, Crisium, and Nectaris (Figure 1A).

Hydrogen occurrence on the lunar surface is in part the result of exposure of the regolith to the solar wind, which consists of a stream of charged particles, mostly hydrogen ions (Haskin and Warren, 1991; Schmitt, 2006; Gillis-Davis, 2008; Clark, 2009; Pieters et al., 2009; Sunshine et al., 2009). For example, areas of immature regolith such as the ejecta surrounding young craters such as Tycho and Copernicus exhibit different optical-maturity trends and low hydrogen values because they have been exposed to the solar wind for a shorter period (Lucey et al., 2000; Johnson et al., 2001). In contrast, older lunar surfaces that have been exposed to the solar wind for relatively long periods typically have greater abundances of hydrogen. Moreover, areas of mature regolith with elevated levels of ilmenite commonly contain hydrogen levels of $60 \mathrm{ppm}$ or more, as the structure of ilmenite is more retentive of implanted hydrogen (Davis, 1980). Although these levels of hydrogen in the regolith are small, hydrogen exists in some regolith in nonpolar areas at sufficient levels of concentration that could be mined for rocket propellants. For example, an approximately $0.4 \mathrm{mi}^{2}\left(\sim 1 \mathrm{~km}^{2}\right)$ area of typical mare regolith that has a concentration of $40 \mathrm{ppm}$ could be mined to a depth of approximately $3.3 \mathrm{ft}(\sim 1 \mathrm{~m})$ to extract an equivalent amount of hydrogen required to launch the space shuttle, which uses a propellant mix of liquid hydrogen and liquid oxygen (Spudis, 1996).

Other areas on the Moon with elevated levels of hydrogen include both polar regions (Figure 2). Initial indications of anomalously high hydrogen levels at the poles came from the Clementine mission in 1994 based on radar signatures consisting of polarized anomalies from deeply shadowed craters such as Shackleton near the South Pole of the Moon (Nozette et al., 1996; Spudis, 1996). The presence of these largeintensity radar anomalies of polarized radar echoes in the south polar region of the Moon is similar to those in permanently shaded craters near the poles of Mercury (Harmon and Slade, 1992; Slade et al., 1992; Butler et al., 1993). However, there has been disagreement 
(A)

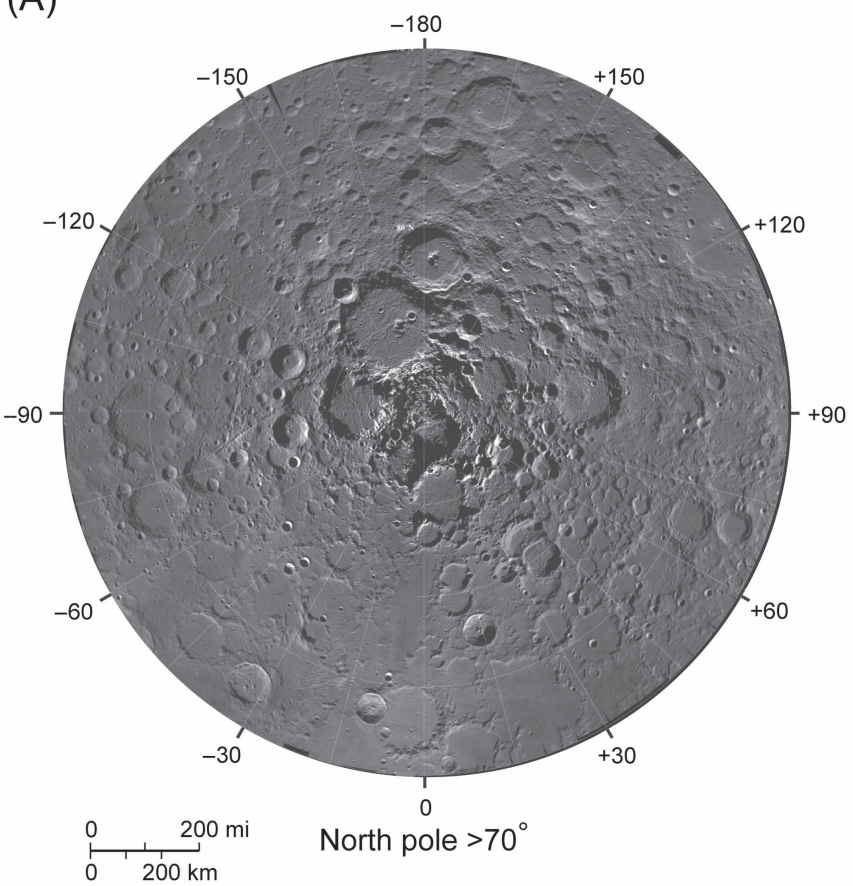

(C)

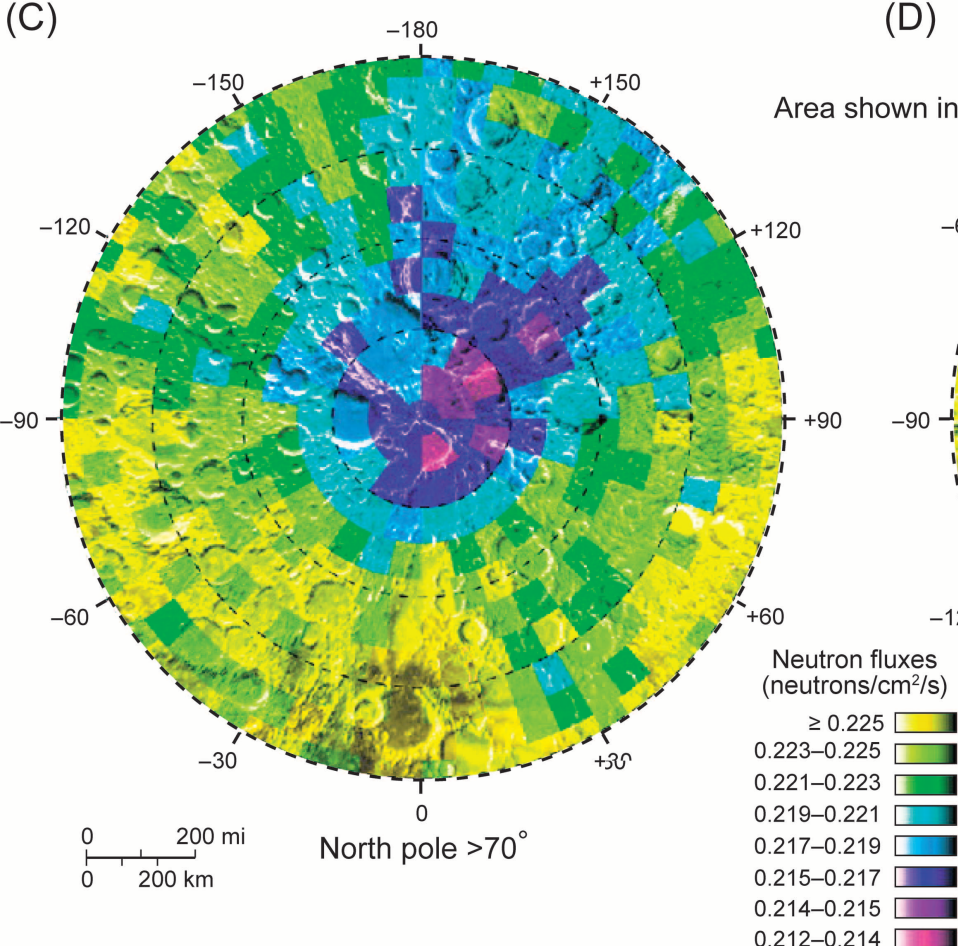

(D)
(B)

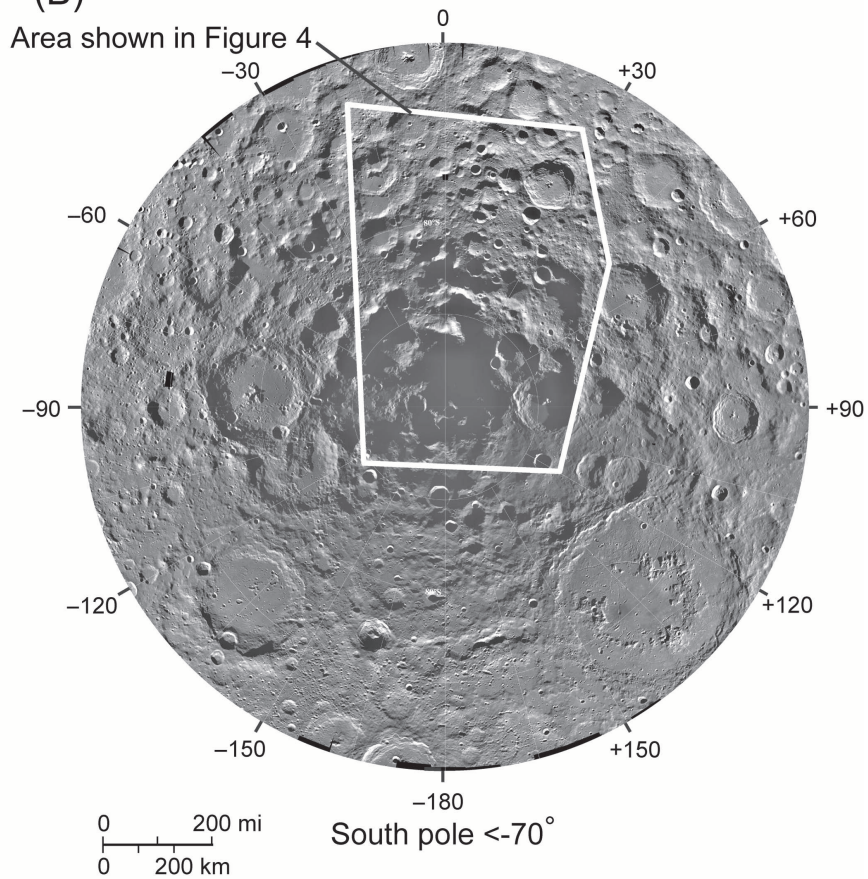

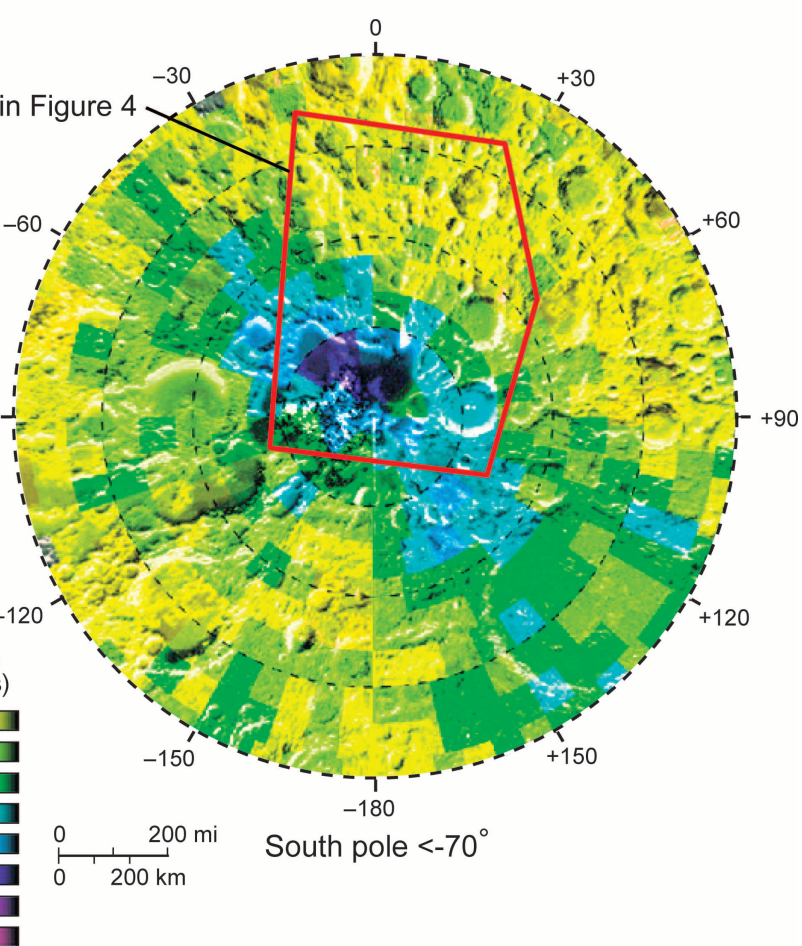

FIGURE 2. Photomosaics of polar areas on the Moon to lat. $70^{\circ}$. (A) North polar area. (B). South polar area. Modified from Clementine ultraviolet-visible (UV-VIS) data, with area in Figure 3 indicated. Polar areas on the Moon with relative abundance of hydrogen inferred from neutrons at reduced epithermal energies overlain on surface-relief maps. Anomalous neutron counting rates are centered on both poles. Relatively low epithermal neutron flux values imply higher hydrogen abundances. Data are from the Lunar Prospector mission. (C) North polar region. (D) South polar region. Modified from Feldman et al. (1998), with neutron-flux values combined for highest values. 
about whether these radar signatures in lunar polar regions indicate surficial ice in suspected cold traps in permanently shadowed craters (Simpson and Tyler, 1999; Nozette et al., 2001). For example, radar images of the lunar poles from Earth-based stations such as the radiotelescope in Arecibo, Puerto Rico, do not suggest the presence of surficial water ice because many similar polarized anomalies appear to also coincide with illuminated areas of blocky crater instead of exclusively from permanently shadowed craters. Moreover, detailed investigations of specific areas in the south polar region at approximately $66 \mathrm{ft}(\sim 20 \mathrm{~m})$ resolution suggest that deeply shadowed craters, such as Shackleton, where possibly concentrated deposits of water ice have been suspected, exhibit radar-scattering properties consistent with rugged inner-crater walls and impact-related ejecta (Campbell et al., 2006). These results suggest that water ice, if present, occurs as disseminated grains at 1 to $2 \%$ abundance (Feldman et al., 2001; Eke et al., 2009). Despite these recent results from Earth-based radar imagery, the presence of enhanced hydrogen levels in both polar regions has been demonstrated by the 1999 Lunar Prospector mission (Feldman et al., 1998) (Figure 2C, D). Neutron data suggest that the hydrogen enrichment is correlated with permanently dark areas (cold traps) near the South Pole, but this relation is not as clearly evident for the North Pole (Elphic et al., 2007).

A leading explanation for anomalously high hydrogen levels in lunar polar regions is that water-ice deposits and other volatiles accumulated as ejecta from lunar impacts from water- and volatile-rich comets and asteroids that settled in areas of permanent shadow in the last 3 b.y. Watson et al. (1961), based on physical chemistry computations and models, suggested that evaporation rates for water and mercury should be low in lunar polar areas because of low temperatures in permanently shadowed areas. Other compounds such as sulfur dioxide, hydrogen chloride, ammonia, and krypton may also be present at the lunar poles but in lesser amounts because of higher evaporation rates. Arnold (1979) estimated that the amount of water delivered to the Moon from cometary impacts during the past 2 b.y. could be as much as approximately $10^{10}$ metric tons $\left(\sim 10^{13} \mathrm{~kg}\right)$. Although volatiles deposited on the lunar surface rapidly sublimate in sunlit areas where the temperature reaches $100^{\circ} \mathrm{C}$ $\left(212^{\circ} \mathrm{F}\right)$ during the day (Bussey et al., 2005), these materials would be stable in areas of permanent shadow where the temperature is slightly above absolute zero. Unilluminated crater floors in polar areas have been believed to be very cold (Vasavada et al., 1999), and recent results from the Lunar Radiometer Experiment (DIVINER) indicate temperatures as low as $35 \mathrm{~K}\left(-397^{\circ} \mathrm{F}\right)$. The Moon's low obliquity $\left(\sim 1.5^{\circ}\right)$ results in significant shadowed and weakly illuminated areas near the North and South poles. These areas consist predominantly of deep crater floors. For example, Bussey et al. (2003) estimate that approximately $2900 \mathrm{mi}^{2}\left(\sim 7500 \mathrm{~km}^{2}\right)$ of such shadowed areas occur within $12^{\circ}$ of the North Pole and approximately $2500 \mathrm{mi}^{2}\left(\sim 6500 \mathrm{~km}^{2}\right)$ of permanent shadows exist within $12^{\circ}$ of the South Pole (Figure 2A, B). These values were obtained by simulating conditions of illumination of bowl-shaped simple craters, less than $12 \mathrm{mi}$ $(<20 \mathrm{~km})$ in diameter. Their study demonstrates that craters as far as $20^{\circ}$ from the pole contain significant amounts of permanent shadow, with seasonal effects being independent of crater size and latitude for latitudes more than $70^{\circ} \mathrm{N}$ or S.

Studies regarding how much cometary and asteroidal impact-related material could have been transported over the surface of the Moon suggest that 20 to $50 \%$ of these volatiles should be in the form of water ice near the poles (Hodges, 1980; Ingersoll et al., 1992; Butler, 1997). Other volatiles of cometary origin that may be present at the poles of the Moon include methane and ammonia ices, as well as lesser amounts of carbon monoxide, carbon dioxide, methyl cyanide $\left(\mathrm{CH}_{3} \mathrm{CN}\right)$, and sulfur (Whipple, 1985). However, several long-term processes operating for billions of years are suspected to have reduced this percentage of water ice and other volatiles, including losses caused by impacts from meteorites (Arnold, 1979), photodissociation from ultraviolet light associated with hydrogen Lyman-alpha emissions (Morgan and Shemansky, 1991), and erosion caused by collisions from other cosmic ray and solar-wind particles (Lanzerotti et al., 1981; Crider and Vondrak, 2003, 2007). Moreover, the absence of bright radar anomalies in lunar polar areas that coincide with specific deeply shadowed craters as observed from terrestrial-based radar data, as well as data from neutron spectroscopy from the Lunar Prospector mission, suggests that the water ice does not occur in surficial layers, but instead in disseminated form at shallow levels of $16 \mathrm{in}$. or more $(\geq 40 \mathrm{~cm}$ ) below a layer of dry regolith (Feldman et al., 1998; Feldman et al., 2000).

In addition to polarized radar anomalies, fluxes of epithermal neutrons are also cited as indirect evidence of water ice at the poles (Figure 2C, D). Neutrons are generated from cosmic rays and other highenergy particles such as protons from the solar wind impacting regolith on planetary bodies with little or 
no atmosphere. Fast neutrons (as much as $700,000 \mathrm{eV}$ ) are initially produced from cosmic ray impacts, with subsequent neutron energy loss through secondary collisions with regolith material (Feldman et al., 2000). Hydrogen in the regolith has a dominant control on the rate of neutron energy loss, as its mass is comparable to that of a neutron, as well as having a large cross sectional area for scattering neutrons at reduced epithermal energies $(0.3-500 \mathrm{eV})$. Quantitative calculations from Lunar Prospector epithermal neutron measurements suggest the presence of $1.5 \mathrm{wt}$. \% of equivalent water ice in polar areas, assuming that the water ice is confined to permanently shaded areas (Lucey, 2009). Even a minor concentration of hydrogen $(100 \mathrm{ppm})$ can produce an epithermal neutron anomaly from the surface of an essentially airless planetary body such as the Moon or Mercury (Drake et al., 1988; Sanin et al., 2009).

Other explanations for the existence of anomalous levels of hydrogen in polar areas on the Moon exist other than from implantation from the solar wind or ejecta from water-ice-rich comets. These include the passage of the Moon through the Earth's magnetosphere, lunar endogenic processes involving outgassing of volatiles (Schultz et al., 2006), and passage of the solar system through interstellar molecular clouds and interplanetary dust. Studies by Talbot and Newman (1977) suggest that the solar system has passed through several giant molecular clouds in the galaxy in the last few billion years. Some of these clouds may have sufficient density to reduce insolation on the Earth and Moon and deposit dust and icerich grains on the Moon. Further isotopic studies of possible water-ice samples from the lunar poles would be necessary to validate this hypothesis and to compare these with results from spectroscopic measurements of giant molecular clouds (Lucey, 2009).

\section{Recent Investigations}

An array of instruments on several recent missions including Kaguya, launched in September 2007, Chang'e 1 (October 2007), Chandrayaan-1 (October 2008), as well as the LRO and Lunar CRater Observation and Sensing Satellite (LCROSS), launched in June 2009 , includes in its mission objectives the improved detection and interpretation of the distribution and quantity of water-ice resources at the lunar poles (Spudis, 2009). These instruments include the synthetic aperture radar (Mini-SAR), the Moon Mineralogy Mapper on Chandrayaan-1 (Figure 3), the Miniature Radio Frequency (Mini-RF) on LRO to obtain high-resolution images of radar backscatter, the lunar

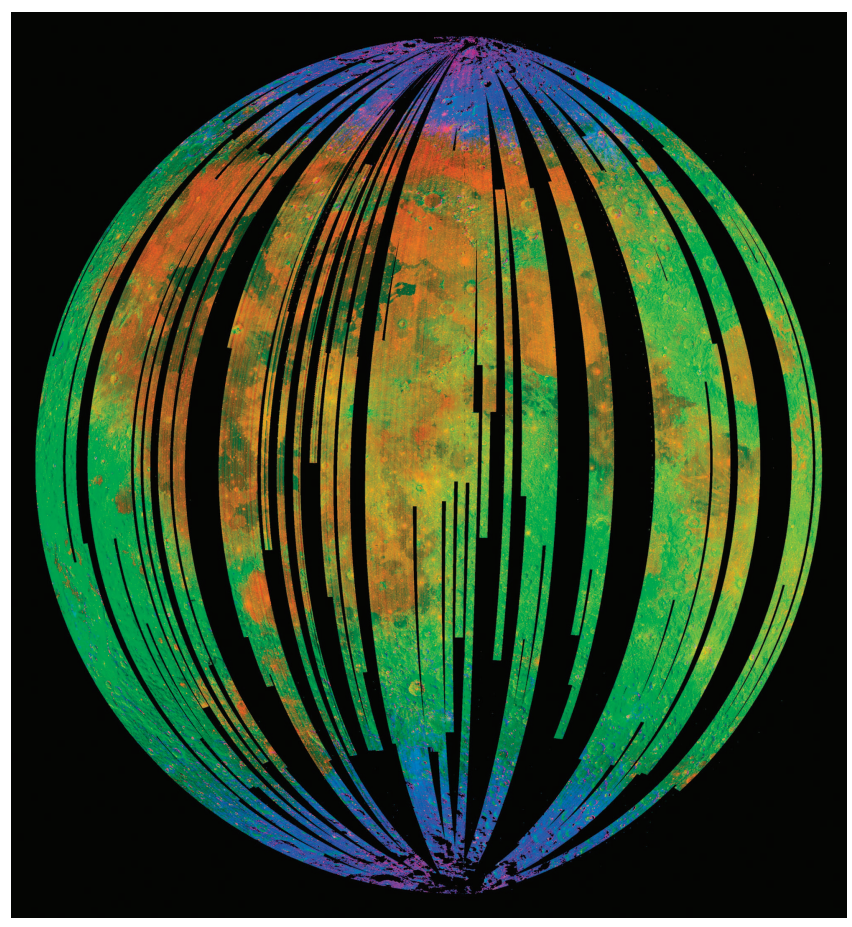

FIGURE 3. Image of the lunar nearside from the Moon Mineralogy Mapper from the Chandrayaan-1 mission. Composed of a three-color composite of reflected nearinfrared radiation, this image shows that small amounts of water and the hydroxyl ion (blue: reflected wavelength of $3.0 \mu \mathrm{m}$ ) are detected on the surface of the Moon, primarily in polar areas. Green areas (reflected infrared radiation at a wavelength of $2.4 \mu \mathrm{m}$ ) correspond to felsicrich highlands. Red areas (2.0 $\mu \mathrm{m}$ wavelength), which correspond to maria, contain iron-bearing pyroxenes. Image courtesy of National Aeronautics and Space Administration (2010a).

exploration neutron detector (LEND) onboard the LRO mission to detect epithermal neutrons also at a higher degree of spatial resolution, and the Lyman Alpha Mapping Project (LAMP), also on the LRO mission, to infer the presence of hydrogen from the reflection of ultraviolet starlight in areas in shadow. Although no individual remote measurement can directly indicate and measure the quantity of suspected water-ice deposits at the lunar poles, a combination of measurements from these instruments, using repeated and detailed imaging at resolutions up to approximately $20 \mathrm{in}$./pixel $(50 \mathrm{~cm} /$ pixel) from the LRO Camera (Robinson et al., 2005; Chin et al., 2007), coupled with temperature measurements by the Lunar Radiometer Experiment (DIVINER) onboard LRO (Hayne et al., 2010; Paige et al., 2010), yielded refined maps of these deposits in polar cold traps. In particular, polar topography was mapped in greater detail from stereo images on the Chandrayaan mission at approximately 


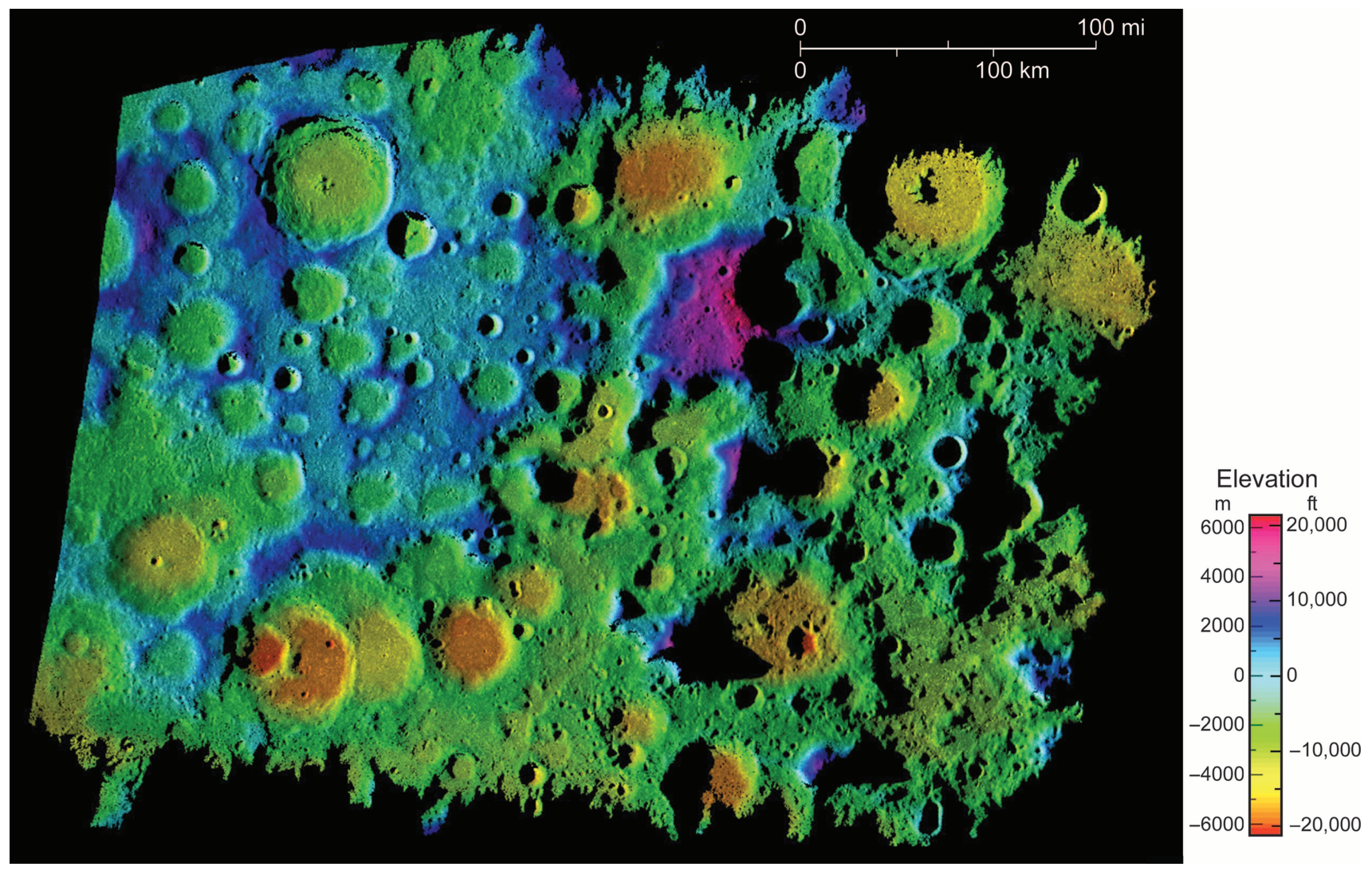

FIGURE 4. High-resolution topographic map of part of the lunar south polar region. Data are from the Goldstone Solar System Radar, Deep Space Network. Map area is shown in Figure 2B. Modified from National Aeronautics and Space Administration (2009d).

$16 \mathrm{ft} /$ pixels $(\sim 5 \mathrm{~m} /$ pixel $)$ to better understand the extent of elevated areas with near-constant illumination and permanently dark cold traps under different seasonal conditions. These maps of polar topography complement existing high-resolution digital elevation maps recently provided from radar imagery at the Jet Propulsion Laboratory, using data collected from the Deep Space Network's Goldstone Solar System Radar (Figure 4). Moreover, topographic data from the Lunar Orbiter Laser Altimeter (LOLA) mission on LRO were derived from a more geographically extensive data set than that from which polar illumination studies were conducted by the Chandrayaan mission (Ramos-Izquierdo et al., 2009). Because solar illumination angles at the poles are $1.5^{\circ}$ or less, subtle slopes that were previously undetected in low-resolution orbital data could significantly affect terrain illumination (Spudis, 2008). Moreover, unique lighting conditions in polar areas may control unusual effects on properties of regolith containing frozen volatile material. The three-dimensional distribution of this material must be understood, whether it is in a complex mixture with fine-grained regolith or distributed as relatively pure isolated lenses and sheets. Knowl- edge of the distribution of these frozen volatiles will have an impact on how to most efficiently implement extraction strategies.

The Mini-SAR imager is a pair of related instruments. The first instrument is an S-band imaging radar on the Chandrayaan-1 mission. The Mini-SAR instrument on LRO is similar to the Chandrayaan-1 instrument but has two bands (S-band and X-band) and is capable of operating in a higher spatial resolution zoom mode. The Mini-SAR on the Chandrayaan-1 mission mapped the dark areas of the lunar poles at an altitude at $60 \mathrm{mi}$ $(100 \mathrm{~km})$, searching for materials of anomalous reflectivity that could indicate water ice. The main objective of the Mini-SAR on Chandrayaan-1 was to conduct systematic mapping from 80 to $90^{\circ}$ latitude for both poles. The key parameter used by the Mini-SAR radar imager to infer water ice was the circular polarization ratio (CPR), expressed as the magnitude of the same sense (the left or right sense of the transmitted circular polarization) divided by the opposite sense of polarization signals. Water-ice reflections have high CPR values that can exceed unity, whereas surface scattering from dry regolith has CPR values that are typically approximately 0.1 to 0.3 (Spudis et al., 2009). 
The Mini-SAR used a radar signal at $2380 \mathrm{MHz}$ and has an illumination incidence angle of $35^{\circ}$. The instrument imaged both poles in SAR mode during every $2 \mathrm{hr}$ orbit, covering both polar regions in a single 28-day mapping window. Images were taken in elongate strips $6 \mathrm{mi}(10 \mathrm{~km})$ wide at a spatial resolution of approximately $250 \mathrm{ft} /$ pixel ( $\sim 75 \mathrm{~m} /$ pixel). These images consisted of opposite-sense image mosaics to characterize dark-area terrain near the poles, images of Stokes parameters described in Raney (2007), and derived maps of CPR and products derived from Stokes parameters such as degree of linear polarization. Stokes parameters are useful supplemental tools in evaluating the nature of lunar radar backscatter by helping to distinguish between reflections from multiple surfaces versus bulk-volume scattering. This characterization is vital in determining if the returned signal is related to a mixture of ice and regolith or dry surficial material.

A principal objective of the Russian LEND instrument on the LRO spacecraft is to measure both the neutron emission from the lunar surface and the local neutron background in orbit, leading to inferring the possible presence of water ice on the Moon and to map the global distribution of hydrogen in the regolith (Mitrofanov et al., 2008, 2010; Sanin et al., 2009). The LEND is a collimated neutron detector system with a 6-mi (10-km)-diameter field of view for the nominal $30 \mathrm{mi}(50 \mathrm{~km})$ orbital altitude. It contains nine neutron sensors that include two sensors of thermal and epithermal neutrons, two Doppler filter sensors for thermal neutrons, four collimated sensors for epithermal neutrons, and one collimated sensor of highenergy neutrons. Measurements of the neutron lunar albedo are also helping to characterize the surface neutron radiation environment, an important constraint for future human lunar missions. Global maps of the neutron radiation environment are being made at a resolution of approximately 40 to $60 \mathrm{mi}(\sim 70-$ $100 \mathrm{~km}$ ). Some surface features with enhanced levels of hydrogen that exhibit great contrast could be imaged with a spatial resolution of $6 \mathrm{mi}(10 \mathrm{~km})$, but for most regions at moderate latitudes, the data are being combined into pixels as large as 12 to $18 \mathrm{mi}(20-30 \mathrm{~km})$. In polar areas, LEND has a sufficiently high sensitivity for detection of enhanced hydrogen at levels of 31 ppm or deposits of water ice occurring at $0.03 \mathrm{wt}$. \% (Sanin et al., 2009).

The objectives of LAMP are to test a recently developed polar and/or night vision and polar-imaging system for future robotic and human missions, identify and localize exposed water-ice resources in per- manently shadowed regions (PSRs), collect landformscale mapping in all PSRs, demonstrate that natural starlight and sky-glow illumination can be used to characterize the lunar surface, and assay the lunar atmosphere and its variability. The LAMP obtained measurements of PSRs, viewing in the nadir direction from LRO. The instrument will measure the signal reflected from the nightside lunar surface and PSRs using Lyman-alpha sky glow and ultraviolet starlight as a light source (Gladstone et al., 2005). The spatial resolution is $1^{\circ}$ or less, with $1^{\circ}$ being equal to approximately $18 \mathrm{mi}(\sim 30 \mathrm{~km})$ at the lunar equator. Reflectance data have yielded albedo maps of PSRs. Spectral data over a range from approximately 600 to $1800 \AA$ were obtained from PSRs, from which abundances of any exposed water-ice deposits were inferred.

The primary objective of LCROSS is to measure the concentration of water ice (ice/dust ratio) in permanently shadowed regolith in lunar polar areas. As a means of detecting water ice in these areas, the upper stage of the Centaur rocket for LRO was impacted at more than $5600 \mathrm{mi} / \mathrm{hr}(>9000 \mathrm{~km} / \mathrm{hr})$ into a permanently shadowed area in Cabeus A crater near the South Pole in October 2009 (National Aeronautics and Space Administration, 2009e, f) (Figures 5-7). The

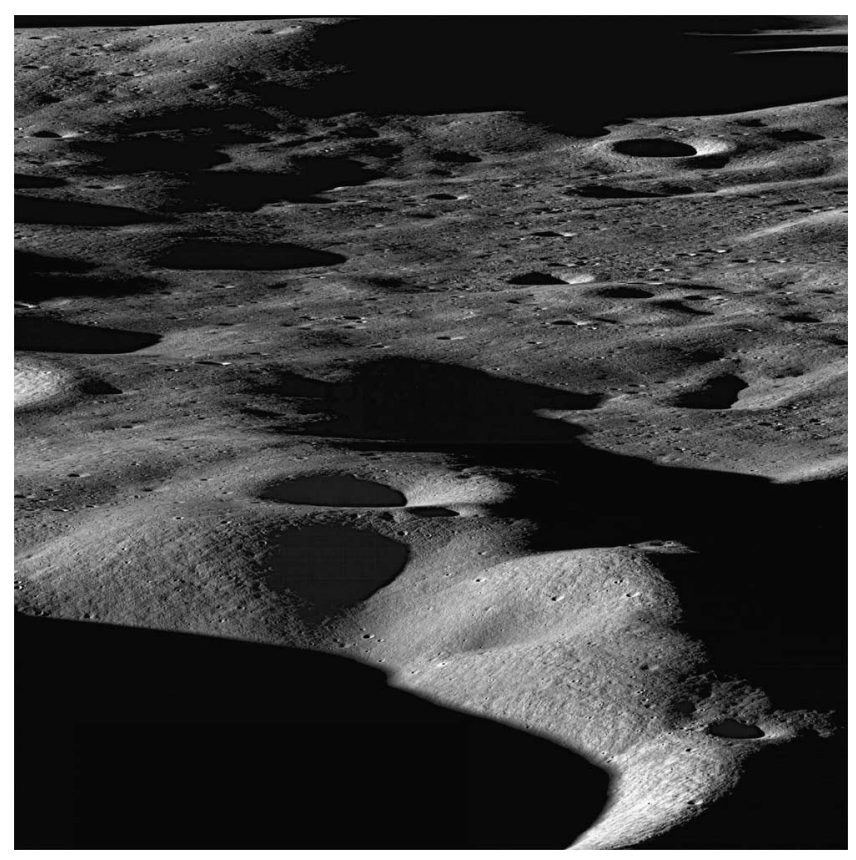

FiGURE 5. Low-angle view across the north rim of Cabeus $A$ (located in Figure 6) from the southwest. Distance from left to right is approximately $45 \mathrm{mi}(\sim 75 \mathrm{~km})$. The Lunar CRater Observation and Sensing Satellite (LCROSS) impact (shown in Figure 7) is located close to the bottom center of the photograph. Courtesy of National Aeronautics and Space Administration and Goddard Space Flight Center. 
objective of this man-made impact was to create an ejecta plume and to detect water ice (hydroxyl [OH] molecules) from the LEND instrument package on the LRO satellite. The impact event was monitored at a variety of spatial (meters to kilometers) and temporal scales (seconds to days) to fully document and characterize the impact process and assess the nonuniform distribution of water ice and other volatiles in the ejecta plume. The impact created a small crater 70 to $100 \mathrm{ft}(21.3-30.5 \mathrm{~m})$ in diameter. The infrared spectrometer on LCROSS recorded absorption bands of water vapor in the ejecta plume at wavelengths of 1.4 and $1.85 \mu \mathrm{m}$. Other spectrometers registered ultraviolet emission at $309 \mathrm{~nm}$, indicating $\mathrm{OH}$ radicals created when water molecules are dissociated by ultraviolet radiation. The ejecta plume in the LCROSS field of view is estimated to have contained approximately $100 \mathrm{~kg}(\sim 220 \mathrm{lb})$ of water vapor (National Aeronautics and Space Administration, $2009 \mathrm{~g}$ ). However, this quantity of water vapor constituted a small fraction of the overall plume material, as early results from LEND indicate that the near-surface rubble inside Cabeus A contains approximately $1 \mathrm{wt}$. \% water. Moreover, other volatiles such as carbon dioxide $\left(\mathrm{CO}_{2}\right)$, carbon monoxide $(\mathrm{CO})$, and organic molecules like methane $\left(\mathrm{CH}_{4}\right)$, methanol $\left(\mathrm{CH}_{3} \mathrm{OH}\right)$, and ethanol $\left(\mathrm{C}_{2} \mathrm{H}_{5} \mathrm{OH}\right)$ may also have been present in the plume based on spectral signatures. Finally, DIVINER data indicate extremely low tem-

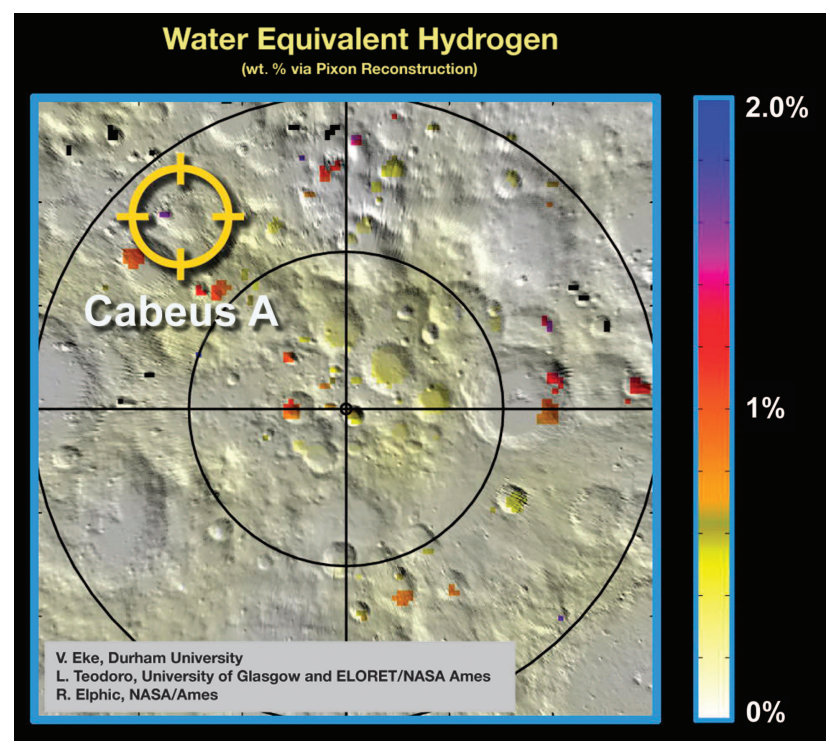

FIGURE 6. Map of water equivalent hydrogen in weight percentage in lunar south polar areas projected from Lunar Prospector data. Image courtesy of National Aeronautics and Space Administration (2010b). Cabeus $A$ is also shown in Figures 5 and 7.

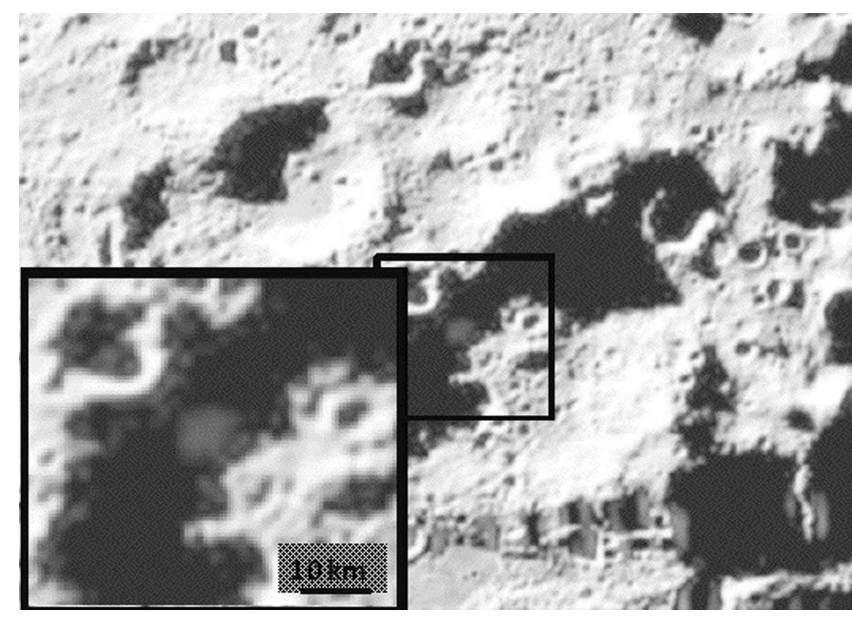

FIGURE 7. Ejecta plume about $20 \mathrm{~s}$ after impact of the upper stage of the Centaur rocket from the Lunar Reconnaissance Orbiter (LRO) satellite, shown in inset. Image is from Lunar CRater Observation and Sensing Satellite (LCROSS) visible camera. Area of plume impact is also shown in Figure 8. Image courtesy of National Aeronautics and Space Administration (2009f).

peratures in permanently shadowed areas in the lunar south polar area, including Cabeus A, where temperatures are less than $40 \mathrm{~K}\left(<-388^{\circ} \mathrm{F}\right)$ (National Aeronautics and Space Administration, 2009h) (Figure 8).

\section{TECHNICAL AND ECONOMIC CONSTRAINTS ON LOCATIONS OF LUNAR FACILITIES}

The Moon has a variety of regions for potential human settlement. Lunar facilities, particularly the primary base of operations, should be strategically located to maximize access to resources and to efficiently transfer material from mining sites to launch facilities, involving minimal propellant consumption and delta-v costs. Five selected lunar regions, summarized in Table 4, consist of (1) polar, (2) nearside equatorial, (3) Oceanus Procellarum, (4) nearside limb, and (5) farside. Settlement in each region will allow access to a different array of lunar resources in varying quantities, consequently with differing technical and economic benefits. For example, there may be limitations to the overall economic viability of some regions where resources such as water ice, volatiles, or fissionable material may be scarce. Other limitations may be in the form of unfavorable location with respect to lineof-sight communication with Earth, locations requiring additional delta-v to access from orbit (although this is dependent on orbital configuration), and regions with a relatively large differential in diurnal temperature that may introduce thermal stress on facilities 


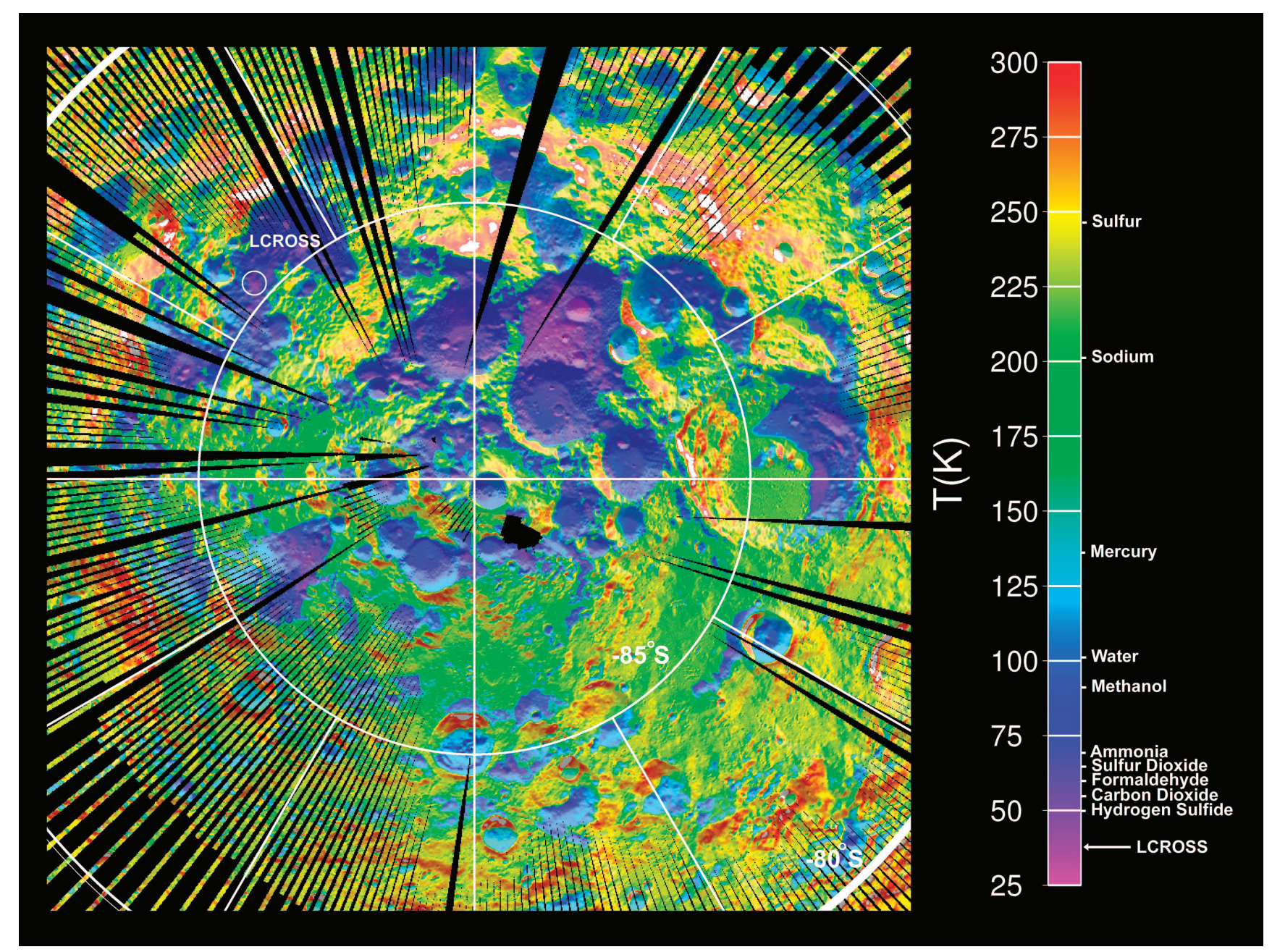

FIGURE 8. Temperature map of the lunar south polar area in degrees Kelvin $(T / K)$, including Lunar CRater Observation and Sensing Satellite (LCROSS) impact site, indicated by a small white circle in the upper left part of the figure. Also shown are condensation temperatures for various volatile elements and compounds. Photograph of plume from impact site is shown in Figure 7. Image courtesy of National Aeronautics and Space Administration (2009h).

and equipment, although this factor could be mitigated by constructing subsurface habitations shielded from daily temperature extremes (Spudis, 1996).

Economic analyses of proposed commercial mining and development of lunar ice resources suggest many possible scenarios (architectures in NASA terminology) for establishing mining and processing facilities on either the lunar surface or alternatively space depots in special lunar orbits either at Lagrangian points $\mathrm{L}_{1}$ and $\mathrm{L}_{2}$ (Rice, 2000; Blair et al., 2002; Duke et al., 2003, 2006). The $\mathrm{L}_{1}$ Lagrangian point is located on a line between the Earth and the Moon, approximately $194,000 \mathrm{mi}(\sim 323,110 \mathrm{~km})$ from the Earth, or $84 \%$ of the way to the Moon. The $\mathrm{L}_{2}$ Lagrangian point is located $36,900 \mathrm{mi}(61,500 \mathrm{~km})$ beyond the lunar farside on the Earth-Moon vector. Lunar orbits at $\mathrm{L}_{1}$ and $L_{2}$ are referred to as LLI and LL2 orbits, respec- tively (Yazdi and Messerschmid, 2008). An efficient lunar mining and settlement architecture involving minimal delta- $v$ costs would include a space depot in an LLI orbit. This space depot, receiving a cargo of lunar water ice from a tanker, would be a facility for electrolyzing water ice into hydrogen and oxygen for fuel and propellant, respectively (Duke et al., 2003). Some of the propellant produced at the $\mathrm{L}_{1}$ site would be used to send the tanker back to the Moon, whereas the remainder would be used to fuel an orbiter transfer vehicle (OTV) to LEO to pick up a new crew or material destined for the Moon. The OTV would then return to the $\mathrm{L}_{1}$ site for refueling and another flight cycle. Success of this lunar architecture would depend on many system elements that include efficient mining of water-ice resources at the poles, transfer of the mined water ice in a reusable tanker to the space depot, safe 
Table 4. Summary of benefits and limitations associated with selected regions on the Moon for possible settlements and facilities.

\begin{tabular}{|c|c|c|c|}
\hline Regions & Resources & Benefits & Limitations \\
\hline Polar areas & Water ice; solar power; volatiles & $\begin{array}{l}\text { Areas with constant or near-constant } \\
\text { solar illumination; elevated hydrogen } \\
\text { levels; minor delta-v cost to access } \\
\text { from LL1* and LL2* orbits }\end{array}$ & $\begin{array}{l}\text { Delta-v cost up to } 4372 \mathrm{~m} / \mathrm{s} \text { to access } \\
\text { landing site from lunar equatorial orbit }\end{array}$ \\
\hline Nearside equatorial areas & $\begin{array}{l}\text { Helium-3 and Ti-rich mare in some } \\
\text { equatorial areas (Tranquillitatis, } \\
\text { Southern Oceanus Procellarum) }\end{array}$ & $\begin{array}{l}\text { Lower delta-v costs to access } \\
\text { landing site from lunar equatorial } \\
\text { orbit; line-of-sight communications } \\
\text { with Earth }\end{array}$ & $\begin{array}{l}\text { Transportation costs from poles if main } \\
\text { facility is in equatorial area; no areas } \\
\text { with near-constant insolation; large } \\
\text { diurnal temperature differential }\end{array}$ \\
\hline Oceanus Procellarum & $\begin{array}{l}\text { Volatiles, uranium and thorium, } \\
\text { helium-3 }\end{array}$ & $\begin{array}{l}\text { KREEP terrane: area of greatest } \\
\text { concentrations of } U \text {, Th; potential } \\
\text { volatile deposits in periphery }\end{array}$ & $\begin{array}{l}\text { Moderate delta-v costs to access from } \\
\text { lunar equatorial orbit; no areas with } \\
\text { near-constant insolation; large diurnal } \\
\text { temperature differential }\end{array}$ \\
\hline Nearside limb areas & $\begin{array}{l}\text { Polar limb areas: water ice; solar } \\
\text { power; volatiles }\end{array}$ & $\begin{array}{l}\text { Proximity to farside radio telescope } \\
\text { locations }\end{array}$ & $\begin{array}{l}\text { Locations must be carefully selected to } \\
\text { optimize access to potential resources }\end{array}$ \\
\hline Farside & $\begin{array}{l}\text { Limited mare areas with helium-3 } \\
\text { (Orientale Basin, Mare Smythii, } \\
\text { Mare Marginis) }\end{array}$ & $\begin{array}{l}\text { Potential locations for radio telescope } \\
\text { installations }\end{array}$ & $\begin{array}{l}\text { Few maria with consequently lower } \\
\text { helium-3 resources; no line-of-sight } \\
\text { communication with Earth; variable } \\
\text { insolation }\end{array}$ \\
\hline
\end{tabular}

${ }^{*}$ LL1 = cis-lunar Lagrangian point 1; LL2 = cis-lunar Lagrangian point 2. 
and reliable fuel and propellant extraction from the water ice, and construction of a large propellantcontainment facility at depot $\mathrm{L}_{1}$ at the site. This architecture assumes a concentration of polar lunar ice at $2 \%$ (Duke et al., 2003).

Alternate strategies could be used in this architecture such as extraction of hydrogen and oxygen from water ice occurring on the Moon instead of on an orbiting space depot. Power for this extraction could be provided either from solar energy (Blair et al., 2002) or nuclear energy from fission (Duke et al., 2006) or nuclear energy from fusion processes from in-situ extraction and processing of helium-3 (Schmitt, 2013). A second architecture involves an additional propellant depot located in LEO and the reusable OTV being shuttled only from LEO to an Earth-GEO, and back to LEO. Economic analyses of both architectures yield similar results, ultimately with significant cost reductions if lunar propellant is provided instead of propellant from Earth only. For example, these architectures are not currently commercially viable. Payload transportation costs from Earth to an $\mathrm{L}_{1}$ site and to the Moon are estimated to be approximately US $\$ 40,900 / \mathrm{lb}$ ( $\sim$ US $\$ 90,000 / \mathrm{kg}$ ) with current systems in 2003 dollars and approximately US $\$ 47,730 / \mathrm{lb}$ ( US $\$ 105,000 / \mathrm{kg}$ ) in 2009 dollars (Duke et al., 2003). This lunar architecture envisages propellant costs to decline to only approximately US $\$ 910 / \mathrm{lb}$ ( US $\$ 2000 / \mathrm{kg}$ ) at the end of a $6 \mathrm{yr}$ period, during which enough lunar-sourced propellant is produced for 30 launch cycles/yr. If propellant is available on the Moon at the assumed $2 \%$ concentration, it would require approximately $12,800 \mathrm{lb}(\sim 5830 \mathrm{~kg})$ of propellant at the $\mathrm{L}_{1}$ site to deliver a 7.8-thousand metric ton $(\mathrm{mt})$ capsule from the $\mathrm{L}_{1}$ site to the surface of the Moon, where it would be refueled to return to $\mathrm{L}_{1}$. The $23.4 \mathrm{mt}$ of propellant required per year at the $\mathrm{L}_{1}$ site for four round-trips of a lunar lander would cost US $\$ 819$ million in 2003 dollars and approximately US \$955 million in 2009 dollars if transported from Earth at current launch costs. However, factoring in lunar surface propellant production systems, the $\mathrm{L}_{1}$ infrastructure, and a reusable lunar lander, the cost of the same propellant if produced on the Moon would be only US $\$ 47$ million in 2003 dollars ( $\sim$ US $\$ 55$ in 2009 dollars [Duke et al., 2003]). Several assumptions constrain this economic scenario, that is, profitability is assumed possible if (1) no development costs or systems will have been developed for other purposes; (2) production is undertaken by private commerce instead of a government-operated project; (3) the concentration of water ice in the regolith exceeds $2 \%$;
(4) that demand for water-ice propellant is greater than that anticipated for launches to GEO by 2016; and (5) improved technology exists (Duke et al., 2003). This economic analysis also assumes that $10 \%$ of the total water-ice market is initially captured, increasing to $100 \%$ in $6 \mathrm{yr}$. Other costs are assumed in the form of system design and development and hardware systems tests, although it is not clear if the salaries of technicians, scientists, and engineers to construct the facilities are factored in the overall analysis.

\section{Polar Regions}

Areas in the region of the lunar poles are commonly cited as optimal sites for lunar settlement (Bussey et al., 2005). A major factor is the presence of topographically high areas (crater rims) that experience nearconstant insolation, ideal for solar power generation (Lucey, 2009; Spudis, 2009). Some of these elevated areas are constantly illuminated during a lunar day in summer (Bussey et al., 2003, 2005). For example, one of these areas of constant illumination occurs on the northern rim of Peary crater, near the North Pole. In contrast to the north polar region, there appear to be fewer elevated areas in the lunar south polar region, except for Shackleton crater, that experience constant solar illumination during the southern winter. This is the result of the lunar South Pole lying inside the rim of the South Pole-Aitken Basin and therefore featuring no areas with sufficient topographic elevation to achieve constant illumination conditions, ideal for solar energy facilities (Bussey et al., 1999).

Other reasons given for polar areas being useful for potential lunar settlements include proximity to potential deposits of water ice and volatiles, although volatiles are present throughout the lunar surface (Clark, 2009; Pieters et al., 2009; Sunshine et al., 2009). In addition, minor variations in diurnal temperature that would have a lesser impact on personnel and equipment because of less thermal stress have been cited as a favorable factor for polar settlements (Bussey et al., 1999). Lower thermal stress in these sunlight areas is hypothesized to be primarily a function of the low angle of insolation because of the Moon's low obliquity of $1.5^{\circ}$. For example, the temperature at the lunar equator ranges from -180 to $100^{\circ} \mathrm{C}(-292$ to $212^{\circ} \mathrm{F}$ ), but the surface temperature for a constantly sunlit, elevated crater-rim area such as Peary crater near the poles is estimated to be $-50^{\circ} \mathrm{C}\left(122^{\circ} \mathrm{F}\right)$ (Heiken et al., 1991). However, it has also been suggested that any structure near the poles presenting a normal face to the Sun will experience nearly the same heating 
effect as a flat panel at the equator at noon $(\mathrm{H}$. $\mathrm{H}$. Schmitt, 2009, personal communication).

A polar Moon base would require a slightly higher delta-v cost (up to $\sim 200 \mathrm{ft} / \mathrm{s}[\sim 60 \mathrm{~m} / \mathrm{s}]$ ) to access from a lunar station in an LL1 or LL2 orbit than would an equatorial Moon base (Farquhar, 1972; Marsden and Ross, 2005). The LL1 and LL2 are defined as lunar orbits accessing the quasi-stable Lagrangian points $\mathrm{L}_{1}$ and $\mathrm{L}_{2}$, respectively (Yazdi and Messerschmid, 2008). In addition, the delta-v cost for transfer between a $60 \mathrm{mi}(96 \mathrm{~km})$ polar lunar orbit and an equatorial landing site linked to a space depot at $\mathrm{L}_{1}$ and $\mathrm{L}_{2}$ would be at least $3000 \mathrm{ft} / \mathrm{s}(915 \mathrm{~m} / \mathrm{s})$ (Faust, 1970).

\section{Nearside Equatorial Regions}

Nearside equatorial areas have traditionally been considered as sites for lunar settlements and landing sites, considering that most of the Apollo missions visited these areas and that they are readily accessible from nonpolar LLOs (Yazdi and Messerschmid, 2008). Some equatorial areas are relatively enriched in titanium-bearing basalts rich in ilmenite and helium3 deposits in Mare Tranquillitatis, Mare Marginis, and isolated areas in the southern part of Oceanus Procellarum (Schmitt, 2006). However, lunar equatorial areas have several negative attributes that may limit their attractiveness for settlement or for launching facilities for shipment of lunar resources to Earth (Table 4). For example, equatorial areas contain no sites with near-constant insolation for maximizing solar power generation. Other economic factors for equatorial areas as one of the principal bases of operations would be the requirement for sufficient power generation during the long ( $\sim 14$-day) lunar night, as well as the expense in transporting water from the poles, although this could be avoided by manufacture of water directly in equatorial areas from hydrogen entrained in the regolith. Nevertheless, assuming this strategy were to be implemented that involved haulage of water from the poles to equatorial areas, this would require significant energy expenditure either via surface haulage or by rocket, as outlined in Lewis (1996). For example, the minimum distance from the poles to the equator is approximately $1640 \mathrm{mi}$ $(\sim 2740 \mathrm{~km})$, and surface transport would require many hundreds of hours of driving time. Moreover, the amount of fuel that would be consumed on such a long route would probably exceed the carrying capacity of the vehicle. Ballistic transport of water from the poles via rockets would also cost energy. Although such a trip would take less than an hour, approximately 600 short tons $(\sim 545,500 \mathrm{~kg})$ of propellant would be consumed in the launching of a vehicle with 400 short tons $(\sim 363,600 \mathrm{~kg})$ of water and 700 short tons ( $\sim 636,400 \mathrm{~kg})$ of hydrogen and oxygen, resulting in more than $60 \%$ of the mined water being expended in transport to the equatorial base.

\section{Oceanus Procellarum}

Oceanus Procellarum is included as a possible region for lunar mining facilities and settlements because it encompasses KREEP terrane, which is relatively rich in REEs, as well as containing the greatest concentration of thorium on the Moon (Jolliff et al., 2000). The southern part of Oceanus Procellarum contains relatively greatest values of thorium and potassium as well as moderate levels of regolith-implanted hydrogen (Figure 1A). However, levels of thorium (Figure 1B) and other incompatible elements may not be sufficiently concentrated throughout much of Oceanus Procellarum to be economically viable and, therefore, exploration efforts should instead be directed toward regolith that has been shed off silicic domes such as Mons Gruithuisen (Glotch et al., 2010).

Marginal areas to Oceanus Procellarum are suspected to contain volatile-rich deposits of exhalatives such as Ina on the southeastern periphery (Schultz et al., 2006). Radon-222 gas, a decay product of uranium and thorium, has been detected from alphaparticle spectrometer instrumentation from Apollo 15 and Apollo 16 missions in the region of the Aristarchus Plateau (Gorenstein et al., 1974) on the northwestern margin of Oceanus Procellarum, where periodic release of exhalatives may occur during episodes of lunar tidal stress. Ina and the Aristarchus Plateau are interpreted to occur within concentric zones of structural weakness related to convergence of compressive seismic waves caused by the 4.2 b.y. impact of the South Pole-Aitken Basin (Schultz, 2008; Schultz and Crawford, 2008).

Both positive and negative factors are associated with a possible base of operations in Oceanus Procellarum (Table 4). For example, there would be minimal delta-v costs to access a base from an equatorial LLO, particularly one in the southern part of the region. In contrast, there would be a lifting penalty in ballistically transporting water-ice resources from polar areas, particularly from the south polar area, which is more distant than the North Pole (see Nearside Equatorial Regions section).

\section{Nearside Limb and Farside Regions}

Nearside limb and farside regions are included together because a lunar base on the nearside limb could 
take advantage of line-of-sight communications with Earth and also be in proximity to a farside radio telescope away from radio interference from Earth. Mare Smythii is an example of an area where a nearside limb lunar facility could be built at the lunar equator and at long. $82^{\circ} \mathrm{E}$ (Spudis and Hood, 1992; Heidmann, 2000). Because of the Moon's $8^{\circ}$ libration in longitude, it would be necessary to have the Moon base at long. $82^{\circ} \mathrm{E}$ to maintain communications with Earth. Likewise, a radio telescope would have to be located at least $8^{\circ} \mathrm{E}$ of the $90^{\circ} \mathrm{E}$ longitude line to avoid disruptive radio noise from Earth. Other nearside limb areas may be attractive for optical telescope installations. For example, the lunar crater Riccioli, located near the Moon's nearside western limb at long. $74.2^{\circ} \mathrm{W}$ and lat. $3.0^{\circ} \mathrm{S}$, has been proposed by Lowman (1985) as a potential site for an astronomical observatory. Riccioli is on the lunar equator, which means that almost all regions of the sky are visible from this locale, as well as being on the lunar nearside, affording line-of-sight data transmission from Earth. Except for locations nearby potential sites for radio and optical telescopes, nearside limb areas would be limited by resource distribution. Access to hydrogen (other than polar hydrogen in water ice) in the regolith in nearside limb areas will be maximized by proximity to areally restricted mare basalts such as those in Mare Smythii, Mare Marginis, Mare Australe, and Mare Humboldtianum (Stuart-Alexander and Howard, 1970), although western fringe areas of Oceanus Procellarum extend many hundreds of kilometers in the northsouth direction.

The lunar farside contains even fewer mare areas than nearside limb areas because of the relative scarcity of extrusive material that was able to rise through the relatively thicker crust. The lunar crust on the farside is typically twice as thick ( $\sim 36 \mathrm{mi}[\sim 60 \mathrm{~km}])$ as that on the nearside crust and is locally up to approximately $54 \mathrm{mi}(\sim 90 \mathrm{~km})$ thick in feldspathic highlands terrain (Zuber et al., 1994; Jolliff et al., 2000; Wieczorek et al., 2006). In addition, the lunar farside has no line-of-sight communication potential with Earth, although a relay satellite in the $\mathrm{L}_{2}$ Lagrangian point could overcome this disadvantage.

\section{SUMMARY}

- The Moon contains a wide variety of resources that can potentially be used for manufacture of propellants for space transportation, volatiles for manufacture of chemicals, and metals for con- struction of solar power facilities, industrial plants, and structures for human habitation. If water ice in polar regions on the Moon is proven to exist in large quantities, these resources could reduce dependency on the Earth for rocket fuel, making human space exploration more economically viable.

- New exploration tools are continuing to be developed to fully and accurately characterize the potential lunar resource base. For example, detection and quantification of water-ice resources in lunar polar regions by current missions involves an array of technologies not commonly used in hydrocarbon exploration on Earth, such as SAR, epithermal neutron detectors, and imaging of reflected ultraviolet starlight using Lymanalpha scattering techniques. These instruments are being used to determine both the nature and three-dimensional distribution of the resource, whether it occurs simply as solar-implanted hydrogen in the shallow regolith or as discrete lenses of water ice, specifically associated with permanently shadowed areas.

- Optimal locations for potential lunar bases and industrial facilities reflect several factors including the distribution of water ice; volatiles such as nitrogen; nuclear materials such helium-3, thorium, and uranium; REEs; and metals including titanium and iron. An important factor is the duration of insolation (sunlight), where solar power facilities could be constructed in polar areas with constant or near-constant illumination. Other factors include location of the primary Moon base, where large delta-v costs could be incurred if such bases require complex orbital trajectories to be accessed from mining facilities or from lunar orbit.

\section{ACKNOWLEDGMENTS}

I acknowledge the helpful reviews of this manuscript by B. J. Thomson and B. L. Jolliff. Matthew Duncan also provided useful comments and suggestions for improving the manuscript. John Ames prepared the illustrations under the direction of Cathy Brown and Joel Lardon, managers, Media Information Technology. Publication support was received from the American Association of Petroleum Geologists (AAPG) Foundation and the Energy Minerals Division of AAPG. Publication was authorized by the Director, Bureau of Economic Geology. 


\section{REFERENCES CITED}

Abell, P. I., P. H. Cadogan, G. Eglinton, J. R. Maxwell, and C. T. Pillinger, 1971, Survey of lunar carbon compounds: I. The presence of indigenous gases and hydrolysable carbon compounds in Apollo 11 and Apollo 12 samples: Proceedings of the Second Lunar Science Conference, v. 2, p. 1843-1863.

Arnold, J. R., 1979, Ice in the lunar polar regions: Journal of Geophysical Research, v. 84, p. 5659-5668, doi:10.1029 /JB084iB10p05659.

Blair, B. R., J. Diaz, M. B. Duke, E. Lamassoure, R. Easter, M. Oderman, and M. Vaucher, 2002, Space resource economic analysis toolkit: The case for commercial lunar ice mining: Final report to the NASA Exploration Team, December 20, 2002: http://www.sps.aero/Key _ComSpace_Articles/Lunar\%20Resources\%20 -\%20Ice\%20Mining.pdf (accessed August 5, 2009).

Braeunig, R. A., 2008, Rocket and space technology: Rocket propellants: http://www.braeunig.us/space/propel .htm (accessed June 23, 2009).

Bugiolacchi, R., and J. E. Guest, 2008, Compositional and temporal investigation of exposed lunar basalts in the Mare Imbrium region: Icarus, v. 197, p. 1-18, doi:10 .1016/j.icarus.2008.04.001.

Bunch, T. E., R. J. William, D. S. McKay, and D. Giles, 1979, Mining and beneficiation of lunar ores, in J. Billingham, W. Gilbreath, B. O'Leary, and B. Gosset, eds., Space resources and space settlements: Washington, D.C., National Aeronautics and Space Administration Special Publication SP-428, p. 275-288.

Bussey, D. B. J., P. D. Spudis, and M. S. Robinson, 1999, Illumination conditions at the lunar South Pole: Geophysical Research Letters, v. 26, p. 1187-1190, doi:10 .1029/1999GL900213.

Bussey, D. B. J., P. G. Lucey, D. Steutel, M. S. Robinson, P. D. Spudis, and K. D. Edwards, 2003, Permanent shadow in simple craters near the lunar poles: Geophysical Research Letters, v. 30, no. 6, p. 1278-1281, doi:10.1029 /2002GL016180.

Bussey, D. B. J., K. E. Fristad, P. M. Schenk, M. S. Robinson, and P. D. Spudis, 2005, Constant illumination at the lunar north pole: Nature, v. 434, p. 842 , doi:10.1038 /434842a.

Butler, B. J., 1997, The migration of volatiles on the surfaces of Mercury and the Moon: Journal of Geophysical Research, v. 102, no. E8, p. 19283-19291, doi:10.1029 /97JE01347.

Butler, B. J., D. O. Muhleman, and M. A. Slade, 1993, Mercury: Full-disk radar images and the detection and stability of ice at the North Pole: Journal of Geophysical Research, v. 98, no. E8, p. 15003-15023, doi:10 .1029/93JE01581.

Campbell, D. B., B. A. Campbell, L. M. Carter, J. L. Margot, and N. J. S. Stacy, 2006, No evidence for thick deposits of ice at the lunar south pole: Nature, v. 443, p. 835837, doi:10.1038/nature05167.

Campbell, M. D., J. D. King, H. M. Wise, B. Handley, J. L.
Conca, and M. David Campbell, 2013, Nuclear power and associated environmental issues in the transition of exploration and mining on Earth to the development of off-world natural resources in the 21st century, in W. A. Ambrose, J. F. Reilly II, and D. C. Peters, eds., Energy resources for human settlement in the solar system and Earth's future in space: AAPG Memoir 101, p. 163-213.

Clark, R. N., 2009, Detection of adsorbed water and hydroxyl on the Moon: Science, v. 326, p. 562-564, doi:10.1126/science.1178105.

Clarke, A. C., 1968, The promise of space: New York, Harper \& Row, 325 p.

Chin, G., et al., 2007, Lunar Reconnaissance Orbiter overview: The instrument suite and mission: Space Science Review, v. 129, p. 391-419, doi:10.1007/s11214 -007-9153-y.

Crider, D. H., and R. R. Vondrak, 2003, Space weathering of ice layers in lunar cold traps: Advances in Space Research, v. 31, no. 11, p. 2293-2298, doi:10.1016 /S0273-1177(03)00530-1.

Crider, D. H., and R. R. Vondrak, 2007, Understanding stratigraphy in lunar polar cold traps (abs.): Lunar and Planetary Science, v. 38, Abstract 2225, 2 p.

Davis Jr., P. A., 1980, Iron and titanium distribution on the Moon from orbital gamma-ray spectroscopy and implications for crustal evolutionary models: Journal of Geophysical Research, v. 85, no. B6, p. 3209-3224, doi:10.1029/JB085iB06p03209.

Drake, D. M., W. C. Feldman, and B. M. Jakosky, 1988, Martian neutron leakage spectra: Journal of Geophysical Research, v. 93, p. 6353-6368, doi:10.1029 /JB093iB06p06353.

Duke, M. B., B. R. Blair, and J. Diaz, 2003, Lunar resource utilization: Implications for commerce and exploration: Advances in Space Research, v. 31, no. 11, p. 24132419, doi:10.1016/S0273-1177(03)00550-7.

Duke, M. B., L. R. Gaddis, G. J. Taylor, and H. H. Schmitt, 2006, Development of the Moon, in B. L. Jolliff, M. A. Wieczorek, C. K. Shearer, and C. R. Neal, eds., New views of the Moon: Reviews in Mineralogy and Geochemistry, v. 60, p. 597-656.

Eke, V. R., L. F. A. Teodoro, and R. C. Elphic, 2009, The spatial distribution of polar hydrogen deposits on the Moon: Icarus, v. 200, p. 12-18, doi:10.1016/j.icarus .2008.10.013.

Elphic, R. C., D. J. Lawrence, W. C. Feldman, B. L. Barraclough, S. Maurice, A. B. Binder, and P. G. Lucey, 1998, Lunar Fe and Ti abundances: Comparison of Lunar Prospector and Clementine data: Science, v. 281, p. 1493-1496, doi:10.1126/science.281.5382 .1493.

Elphic, R. C., V. R. Eke, L. F. A. Teodoro, D. J. Lawrence, and D. B. J. Bussey, 2007, Models of the distribution and abundance of hydrogen at the lunar south pole: Geophysical Research Letters, v. 34, no. 13, L13204, 5 p., doi:10.1029/2007GL029954.

European Space Agency, 2009, International Space Station: 
http://www.esa.int/esaHS/ESAQHAOVMOC_iss_0.html (accessed July 24, 2009).

Farquhar, R. W., 1972, A halo-orbit lunar station: Astronautics and Aeronautics, v. 10, no. 6, p. 59-63.

Faust, N. L., 1970, Launch and polar orbit transfer velocity requirements for the LM-B (Space Tug): National Aeronautics and Space Administration-Manned Spacecraft Center Internal Note 70-FM-37, variously paginated.

Feldman, W. C., S. Maurice, A. B. Binder, B. L. Barraclough, R. C. Elphic, and D. J. Lawrence, 1998, Fluxes of fast and epithermal neutrons from Lunar Prospector: Evidence for water ice at the lunar poles: Science, v. 298, p. 1496-1500, doi:10.1126/science.281.5382.1496.

Feldman, W. C., D. J. Lawrence, R. C. Elphic, B. L. Barraclough, S. Maurice, I. Genetay, and A. B. Binder, 2000, Polar hydrogen deposits on the Moon: Journal of Geophysical Research, v. 105, no. E2, p. 4175-4195, doi:10.1029/1999JE001129.

Feldman, W. C., et al., 2001, Evidence for water ice near the lunar poles: Journal of Geophysical Research, v. 106, no. E10, p. 23231-23252, doi:10.1029/2000JE001444.

Foing, B. H., 2007, Results from the SMART-1 lunar mission: Highlights of Astronomy, v. 14, p. 329-330.

Gasnault, O., R. C. Elphic, D. J. Lawrence, S. Karunatillake, C. d'Uston, and O. Forni, 2008, A gamma-ray perspective from Lunar Prospector (abs.): 39th Lunar and Planetary Science Conference, Abstract 2111, 2 p., doi:10.1017/S1743921307010885.

Gillis, J. J., B. J. Jolliff, and R. C. Elphic, 2003, A revised algorithm for calculating $\mathrm{TiO}_{2}$ from Clementine UVVIS data: A synthesis of rock, soil, and remotely sensed $\mathrm{TiO}_{2}$ concentrations: Journal of Geophysical Research, v. 108, no. E2, 18 p., doi:10.1029/2001JE001515.

Gillis, J. J., B. L. Jolliff, and R. L. Korotev, 2004, Lunar surface geochemistry: Global concentrations of Th, K, and $\mathrm{FeO}$ as derived from Lunar Prospector and Clementine data: Geochimica et Cosmochimica Acta, v. 68, p. 37913805, doi:10.1016/j.gca.2004.03.024.

Gillis-Davis, J. J., 2008, Improved lunar hydrogen compositions by reducing the effects of Sm and Gd concentration on lunar prospector epithermal neutron data (abs.): Lunar and Planetary Science, v. 39, Abstract 2549, 2 p.

Gladstone, G. R., S. A. Stern, K. D. Retherford, R. Black, J. R. Scherrer, D. C. Slater, J. M. Stone, P. D. Feldman, and D. Crider, 2005, LAMP: The Lyman Alpha Mapping Project aboard the NASA Lunar Reconnaissance Orbiter mission, in R. B. Hoover, G. V. Levin, A. Y. Rozanov, and G. R. Gladstone, eds., Astrobiology and planetary missions, Society of Photo-Optical Instrumentation Engineers (International Society for Optics and Photonics) Proceedings, v. 5906, Article 59061A, 9 p.

Glotch, T. D., et al., 2010, Identification of highly silicic features on the Moon (abs.): Lunar and Planetary Science, v. 41, Abstract 1780, 2 p.

Gordon, J. S., 2004, An empire of wealth: New York, HarperCollins Publishers, 460 p.

Gorenstein, P., L. Golub, and P. Bjorkholm, 1974, Radon emanation from the Moon, spatial and temporal variability: The Moon, v. 9, p. 129-140, doi:10.1007 /BF00565399.

Hagerty, J. J., D. J. Lawrence, B. R. Hawke, and L. R. Gaddis, 2009, New estimates of thorium abundances for the Rima Bode pyroclastic glass deposit (abs.): Lunar and Planetary Science, v. 40, Abstract 1852, 2 p.

Haines, E. L., and A. E. Metzger, 1980, Lunar highland crustal models based on iron concentrations: Isostasy and center-of-mass displacement: Proceedings of the 11th Lunar and Planetary Science Conference, p. 689-718.

Harmon, J. K., and M. A. Slade, 1992, Radar mapping of Mercury: Full-disk images and polar anomalies: Science, v. 258, p. 640-643.

Haskin, L. A., and P. H. Warren, 1991, Lunar chemistry, in G. Heiken, D. Vaniman, and B. French, eds., Lunar sourcebook: A user's guide to the Moon: Cambridge, Cambridge University Press, p. 357-474.

Hayne, P. O., B. T. Greenhagen, D. A. Paige, M. C. Foote, and M. A. Siegler, 2010, DIVINER observations of the LCROSS impact (abs.): Lunar and Planetary Science, v. 41, Abstract 2484, 2 p.

Heidmann, J., 2000, A proposal for a radio frequency interference-free dedicated lunar far side crater for high-sensitivity radioastronomy: Programmatic issues: Acta Astronautica, v. 46, no. 8, p. 555-558, doi:10 .1016/S0094-5765(00)00002-3.

Heiken, G., D. Vaniman, and B. French, 1991, eds., Lunar sourcebook: A user's guide to the Moon: Cambridge, Cambridge University Press, 736 p.

Hiesinger, H., R. Jaumann, G. Neukum, and J. W. Head III, 1998 , On the relation of age and titanium content of lunar mare basalts (abs.): Lunar and Planetary Science, v. 29, Abstract 1243, 2 p.

Hodges Jr., R. R., 1980, Lunar cold traps and their influence on argon-40: Proceedings of the 11th Lunar and Planetary Science Conference, p. 2463-2477.

Howard, K. A., J. W. Head, and G. A. Swann, 1972, Geology of Hadley Rille, in E. King, ed., Proceedings of the Third Lunar Science Conference: Cambridge, Massachusetts, The MIT Press, v. 1, p. 1-14.

Ingersoll, A. P., T. Svitek, and B. C. Murray, 1992, Stability of polar frosts in spherical bowl-shaped craters on the Moon, Mercury, and Mars: Icarus, v. 100, p. 40-47, doi:10.1016/0019-1035(92)90016-Z.

Ionov, D., A. W. Hofmann, C. Merlet, A. A. Gurenko, E. Hellebrand, G. Montagnac, P. Gillet, and V. S. Prikhodko, 2006, Discovery of whitlockite in mantle xenoliths: Inferences for water- and halogen-poor fluids and trace element residence in the terrestrial upper mantle: Earth and Planetary Science Letters, v. 244, p. 201217, doi:10.1016/j.epsl.2006.02.012.

Johnson, J. R., S. Maurice, W. Feldman, D. Lawrence, P. Lucey, and T. Swindle, 2001, Hydrogen distribution from Lunar Prospector epithermal neutron data: Correlations with impact craters and landing site examples (abs.): 32nd Lunar and Planetary Science Conference, Abstract 1440, 2 p. 
Jolliff, B. L., J. L. Gillis, L. A. Haskin, R. L. Korotev, and M. A. Wieczorek, 2000, Major lunar crustal terranes: Surface expressions and crust-mantle origins: Journal of Geophysical Research, v. 105, no. E2, p. 4197-4216, doi:10 .1029/1999JE001103.

Kaplan, I. R., and J. W. Smith, 1970, Concentration and isotopic composition of carbon and sulfur in Apollo 11 lunar samples: Science, v. 167, p. 541-543.

Kerslake, T. W., F. M. Haraburda, and J. P. Riehl, 2000, Solar power system options for the Radiation and Technology Demonstration Spacecraft: IEEE Xplore, Paper AIAA-2000-2807, p. 47-57.

Lanzerotti, L. J., W. L. Brown, and R. E. Johnson, 1981, Ice in the polar regions of the Moon: Journal of Geophysical Research, v. 86, p. 3949, doi:10.1029/JB086iB05p03949.

Latham, G., M. Ewing, F. Press, G. Sutton, J. Dorman, Y. Nakamura, N. Toksöz, R. Wiggins, J. Derr, and F. Duennebier, 1970, Apollo 11 passive seismic experiment: Science, v. 167, p. 455-467.

Lawrence, D. J., W. C. Feldman, B. L. Barraclough, A. B. Binder, R. C. Elphic, S. Maurice, and D. R. Thomsen, 1998, Global elemental maps of the Moon: The Lunar Prospector gamma-ray spectrometer: Science, v. 281, p. 1484-1489, doi:10.1126/science.281.5382.1484.

Lewis, J. S., 1996, Mining the sky: Reading, Massachusetts, Addison-Wesley Publishing Company, Inc., 274 p.

Lowman Jr., P. D., 1985, Lunar bases: A post-Apollo evaluation, in W. W. Mendell, ed., Lunar bases and space activities of the 21st century: Houston, Texas, Lunar and Planetary Science Institute, p. 35-46.

Lucey, P. G., 2009, The poles of the Moon: Elements, v. 5, p. 41-46, doi:10.2113/gselements.5.1.41.

Lucey, P. G., G. J. Taylor, and E. Malaret, 1995, Abundance and distribution of iron on the Moon: Science, v. 268, p. 1150-1153, doi:10.1126/science.268.5214.1150.

Lucey, P. G., D. T., Blewett, G. J. Taylor, and B. R. Hawke, 2000, Imaging of lunar surface maturity: Journal of Geophysical Research, v. 105, p. 20,377-20,386, doi:10 .1029/1999JE001110.

Marsden, J. E., and S. D. Ross, 2005, New methods in celestial mechanics and mission design: Bulletin of the American Mathematical Society, v. 43, no. 1, p. 43-73.

Marvin, U. B., 1973, The Moon after Apollo: M. I. T. Technology Review, v. 75, no. 8, p. 12-23.

Marvin, U. B., J. A. Wood, G. J. Taylor, J. B. Reed Jr., B. N. Powell, J. S. Dickey Jr., and J. F. Bower, 1971, Relative proportions and probable sources if rock fragments in the Apollo 12 soil samples, in A. A. Levinson, ed., Proceedings of the Second Lunar Science Conference, Supplement 2: Cambridge, Massachusetts, M. I. T Press, p. 679-700.

Mathew, K. J., and K. Marti, 2000, Lunar nitrogen: Indigenous signature and cosmic-ray production rate: Earth and Planetary Science Letters, v. 184, p. 659-669, doi:10.1016/S0012-821X(00)00327-7.

Mendell, W. W., 1985, ed., Lunar bases and space activities of the 21st century: Houston, Texas, The Lunar and Planetary Institute, $856 \mathrm{p}$.
Meyer, C., and S. V. Yang, 1988, Tungsten-bearing yttrobetafite in lunar granophyre: American Mineralogist, v. 73, p. 1420-1425.

Mitrofanov, I. G., et al., 2008, Experiment LEND of the NASA Lunar Reconnaissance Orbiter for high-resolution mapping of neutron emission of the Moon: Astrobiology, v. 8, no. 4, p. 794-804, doi:10.1089/ast.2007.0158.

Mitrofanov, I. G., et al., 2010, LEND experiment onboard LRO: Testing local areas with high concentrations of hydrogen at the lunar poles (ext. abs.): Lunar and Planetary Science, v. 41, Abstract 2250, 2 p.

Mokhov, A. V., P. M. Kartashov, O. A. Bogatikov, L. O. Magazina, N. A. Ashikhmina, and E. V. Koporulina, 2008, Find of unusual complex oxides and ç-bronze in lunar regolith: Doklady Earth Sciences, v. 421A, no. 6, p. 923-925, doi:10.1134/S1028334X08060135 .

Monterde, M. P., M. G. Haines, A. E. Dangor, A. K. Malik, and D. G. Fearn, 1997, Kaufman-type xenon ion thruster coupling plasma: Langmuir probe measurements: Journal of Physics D Applied Physics, v. 30, p. 842-855, doi:10.1088/0022-3727/30/5/017.

Morgan, T. H., and D. E. Shemansky, 1991, Limits to the lunar atmosphere: Journal of Geophysical Research, v. 96, no. A2, p. 1351, doi:10.1029/90JA02127.

National Aeronautics and Space Administration, 2003, Rockets: An educator's guide with activities in science, mathematics, and technology: Document EG-2003 -01-108-HQ: http://www.nasa.gov/pdf/153410main _Rockets.Guide.History.pdf (accessed July 28, 2009).

National Aeronautics and Space Administration, 2009a, Constellation: NASA's new spacecraft: Ares, Orion, and Altair lunar lander: http://www.nasa.gov/mission _pages/constellation/altair/altair.html (accessed July 9, 2009).

National Aeronautics and Space Administration, 2009b, Apollo mission: http://spaceflight.nasa.gov/history /apollo/apollo_mission.html (accessed July 28, 2009).

National Aeronautics and Space Administration, 2009c, Project Apollo: A retrospective analysis: http://history .nasa.gov/Apollomon/Apollo.html (accessed July 29, 2009).

National Aeronautics and Space Administration, 2009d, Moon's rugged south polar region composite: http ://www.nasa.gov/topics/moonmars/features/moon -20090618.html (accessed November 20, 2009).

National Aeronautics and Space Administration, 2009e, Lunar CRater Observation and Sensing Satellite (LCROSS): http://lcross.arc.nasa.gov/impact.htm (accessed January 4, 2010).

National Aeronautics and Space Administration, 2009f, LCROSS visible camera image, Cabeus A: http://www .nasa.gov/images/content/509507main_plume.jpg (accessed February 28, 2011).

National Aeronautics and Space Administration, 2009g, Lunar CRater Observation and Sensing Satellite (LCROSS) mission update: http://www.nasa.gov/mission_pages /LCROSS/main/prelim_water_results.html (accessed January 8, 2010). 
National Aeronautics and Space Administration, 2009h, LRO Diviner Lunar Radiometer Experiment surface temperature map: http://www.nasa.gov/images /content/490554main_paige_full.jpg (accessed February 28, 2011).

National Aeronautics and Space Administration, 2010a, Lunar surficial mineralogy map from Moon Mineralogy Mapper: http://www.nasa.gov/images/content /388698main_1-M3color-clean-full.jpg (accessed March 4, 2011).

National Aeronautics and Space Administration, 2010b, South pole potential water concentrations based on data from Lunar Prospector: http://www.nasa.gov /centers/ames/images/content/385726main_ARC -LCROSS-WEH-Part1.jpg (accessed March 4, 2011).

Nozette, S. C., L. Lichtenberg, P. Spudis, R. Bonner, W. Ort, E. Malaret, M. Robinson, and E. M. Shoemaker, 1996, The Clementine bistatic radar experiment: Science, v. 274, p. 1495-1498, doi:10.1126/science.274 .5292 .1495 .

Nozette, S. C., P. D. Spudis, M. S. Robinson, D. B. J. Bussey, C. Lichtenberg, and R. Bonner, 2001, Integration of lunar polar remote-sensing data sets: Evidence for ice at the lunar south pole: Journal of Geophysical Research, v. 106, no. E10, p. 23253-23266.

O'Hara, M. J., 2000, Flood basalts, flood basalts or topless Bushvelds? Lunar petrogenesis revisited: Journal of Petrology, v. 41, no. 11, p. 1545-1651, doi:10.1093 /petrology/41.11.1545.

O'Hara, M. J., G. M. Biggar, P. G. Hill, B. Jefferies, and D. J. Humphries, 1974, Plagioclase saturation in lunar hightitanium basalt: Earth and Planetary Science Letters, v. 21, p. 253-268, doi:10.1016/0012-821X(74)90160-5.

Paige, D. A., et al., 2010, DIVINER lunar radiometer experiment: Early mapping mission results (abs.): Lunar and Planetary Science, v. 41, Abstract 2267, 2 p.

Papike, J. J., G. Ryder, and C. K. Shearer, 1998, Lunar samples, in J. J. Papike, ed., Planetary materials: Reviews in mineralogy and geochemistry: Washington, D.C., Mineralogical Society of America, p. 5.1-5.234.

Patterson, M. J., J. E. Foster, T. W. Haag, V. K. Rawlin, G. C. Soulas, and R. F. Roman, 2002, NEXT: NASA's evolutionary xenon thruster: American Institute of Aeronautics and Astronautics, AIAA Paper 2002-3832, 6 p.

Pielke Jr., R. A., and R. Byerly Jr., 1992, The Space Shuttle program: Performance versus promise, in R. Byerly, ed., Space policy alternatives: Boulder, Colorado, Westview Press, p. 223-245.

Pieters, C. M., 1978, Mare basalt types on the front side of the Moon: A summary of spectral reflectance data: Proceedings of the 9th Lunar and Planetary Science Conference, v. 9, p. 2825-2849.

Pieters, C. M., et al., 2009, Character and spatial distribution of $\mathrm{OH} / \mathrm{H}_{2} \mathrm{O}$ on the surface of the Moon seen by $\mathrm{M}^{3}$ on Chandrayaan-1: Science, v. 326, p. 568-571, doi:10 $.1126 /$ science. 1178658 .

Pillinger, C. T., and G. Eglinton, 1977, The chemistry of carbon in the lunar regolith: Philosophical Transac- tions of the Royal Society of London Series A, v. 285, p. 369-377.

Ramos-Izquierdo, L., et al., 2009, Optical system design and integration of the Lunar Orbiter Laser Altimeter: Applied Optics, v. 48, no. 16, p. 3035-3049, doi:10 .1364/AO.48.003035.

Raney, R. K., 2007, Hybrid-polarity SAR architecture: Institute of Electrical and Electronics Engineers Transactions on Geoscience and Remote Sensing, v. 45, p. 33973404, doi:10.1109/TGRS.2007.895883.

Rice, E. E., 2000, Development of lunar ice/hydrogen recovery system architecture: Final report prepared for NASA Institute for Advanced Concepts: NASA/NIAC Research Grant 07600-021 OTC-G083-FR-2000-1, http://www.niac.usra.edu/files/studies/final_report /341Rice.pdf (accessed August 5, 2009).

Robinson, M. S., E. M. Eliason, H. Hiesinger, B. L. Jolliff, A. S. McEwen, M. C. Malin, M. A. Ravine, D. Roberts, P. C. Thomas, and E. P. Turtle, 2005, LROC-Lunar Reconnaissance Orbiter Camera (abs.): 36th Lunar and Planetary Science Conference, Abstract 1576, 2 p.

Saal, A. E., E. H. Hauri, M. Lo Cascio, J. A. Van Orman, M. C. Rutherford, and R. F. Cooper, 2008, Volatile content of lunar glasses and the presence of water in the Moon's interior: Nature, v. 454, p. 192-196, doi:10.1038 /nature07047.

Sanin, A. B., et al., 2009, Lunar exploration neutron detector (LEND) for NASA Lunar Reconnaissance Orbiter: Searching for the water ice (ext. abs.): 40th Lunar and Planetary Science Conference, Abstract 1249, 2 p.

Schmitt, H. H., 2006, Return to the Moon: Praxis Publishing, Ltd., New York, NY, 335 p.

Schmitt, H. H., 2008, The case for lunar maria as potential layered extrusives (abs.): AAPG Search and Discovery, http://www.searchanddiscovery.net/abstracts/html /2008/intl_capetown/abstracts/464240.htm (accessed July 21, 2009).

Schmitt, H. H., 2013, Lunar helium-3 energy resources, in W. A. Ambrose, J. F. Reilly II, and D. C. Peters, eds., Energy resources for human settlement in the solar system and Earth's future in space: AAPG Memoir 101, p. $33-51$.

Schultz, P. H., 2008, The Moon: Dead or alive? (abs.): AAPG 2008 Annual Convention and Exhibition Abstracts Volume, v. 17, p. 182.

Schultz, P. H., and D. A. Crawford, 2008, Consequences of forming the South-Pole-Aitken Basin (ext. abs.): Lunar and Planetary Science, v. 39, Abstract 2451, 2 p.

Schultz, P. H., M. I. Staid, and C. M. Pieters, 2006, Lunar activity from recent gas release: Nature, v. 444, p. $441-$ 445.

Seedhouse, E., 2009, Lunar outpost: The challenges of establishing a human settlement on the Moon: Chichester, United Kingdom, Praxis Publishing, Ltd., 292 p.

Sheehan, W., 1992, Worlds in the sky: Tucson, Arizona, University of Arizona Press, 243 p.

Short, N., 1975, Planetary geology: Englewood Cliffs, New Jersey, Prentice-Hall, Inc., 361 p. 
Simpson, R., and G. L. Tyler, 1999, Reanalysis of Clementine bistatic radar data from the lunar South Pole: Journal of Geophysical Research, v. 104, no. E2, p. 38453862, doi:10.1029/1998JE900038.

Slade, M. A., B. J. Butler, and D. O. Muhleman, 1992, Mercury radar imaging: Evidence for polar ice: Science, v. 258, p. 635-640, doi:10.1126/science.258.5082.635.

Solomon, S. C., and J. W. Head III, 1979, Vertical movement in mare basins: Relation to mare emplacement, basin tectonics, and lunar thermal history: Journal of Geophysical Research, v. 84, p. 1667-1682, doi:10 .1029/JB084iB04p01667.

Spudis, P. D., 1996, The once and future Moon: Washington, D.C., Smithsonian Institution Press, 308 p.

Spudis, P. D., 2008, Lunar polar exploration: Questions, issues and missions (abs.): Lunar and Planetary Science, v. 39, Abstract 1359, 2 p.

Spudis, P. D., 2009, Back to the Moon: Nature Geoscience, v. 2, p. $234-236$.

Spudis, P. D., and L. L. Hood, 1992, Geological and geophysical field investigations from a lunar base at Mare Smythii, in W. W. Mendell, ed., Second Conference on Lunar Bases and Space Activities of the 21st Century: NASA Conference Publication 3166, v. 1, p. $163-174$.

Spudis, P. D., et al., 2009, The Mini-SAR imaging radar on the Chandrayaan-1 mission to the Moon (abs.): Lunar and Planetary Science, v. 40, 1098.

Stuart-Alexander, D. E., and K. A. Howard, 1970, Lunar maria and circular basins: A review: Icarus, v. 12, p. 440-456, doi:10.1016/0019-1035(70)90013-8.

Sunshine, J. M., T. L. Farnham, L. M. Feaga, O. Groussin, F. Merlin, R. E. Milliken, and M. F. A'Hearn, 2009, Temporal and spatial variability of lunar hydration as observed by the Deep Impact spacecraft: Science, v. 326, p. 565-568, doi:10.1126/science.1179788.

Talbot, R. J., and M. J. Newman, 1977, Encounters between stars and dense interstellar clouds: Astrophysical Journal Supplement, v. 34, p. 295-308.

Taylor, G. J., and L. M. V. Martel, 2003, Lunar prospecting: Advances in Space Research, v. 31, no. 11, p. 24032412.

Thomson, B. J., E. B. Grosfils, D. B. J. Bussey, and P. D. Spudis, 2009, A new technique for estimating the thickness of mare basalts in Imbrium Basin: Geophys- ical Research Letters, v. 36, no. L12201, 5 p., doi:10.1029/2009GL037600.

Vasavada, A. R., D. A. Paige, and S. E. Wood, 1999, Nearsurface temperatures on Mercury and the Moon and the stability of polar ice deposits: Icarus, v. 141, p. 179193, doi:10.1006/icar.1999.6175.

Wasserburg, G. J., G. Turner, F. Tera, F. A. Podesek, D. A. Papanastassiou, and J. C. Huneke, 1972, Comparison of the Rb-Sr, K-Ar, and U-Th-Pb ages: Lunar chronology and evolution (ext. abs.), in C. Watkins, ed., Third Lunar Science Conference: Houston, Lunar Science Institute, p. 695-697.

Wasson, J. T., and P. H. Warren, 1980, Further foraging for pristine non-mare rock: Correlations between geochemistry and longitude: Proceedings of the 11th Lunar and Planetary Science Conference, p. 431-470.

Watson, K. W., B. C. Murray, and H. Brown, 1961, The behavior of volatiles on the lunar surface: Journal of Geophysical Research, v. 66, no. 9, p. 3033-3045, doi:10 .1029/JZ066i009p03033.

Whipple, F. L., 1985, The mystery of comets: Washington, D. C., Smithsonian Institution Press, 276 p.

Whitford-Stark, J. L., and J. W. Head III, 1980, Stratigraphy of Oceanus Procellarum basalts, sources and styles of emplacement: Journal of Geophysical Research B, v. $85 / 11$, p. $6579-6609$.

Wieczorek, M. A., et al., 2006, The constitution and structure of the lunar interior, in B. J. Jolliff, M. A. Wieczorek, C. K. Shearer, and C. R. Neal, eds., New views of the Moon: Mineralogical Society of America, Reviews in Mineralogy and Geochemistry, v. 60, p. 221-364, doi:10.2138/rmg.2006.60.3.

Wilhelms, D. E., 1987, The geologic history of the Moon: U.S. Geological Survey Professional Paper 1348, 302 p.

Wilhelms, D. E., and J. F. McCauley, 1971, Geologic map of the near side of the Moon: U.S. Geological Survey Map I-703: Washington, D.C., U.S. Government Printing Office, $26 \mathrm{p}$.

Yazdi, K., and E. Messerschmid, 2008, A lunar exploration architecture using lunar libration point one: Aerospace Science and Technology, v. 12, p. 231-240.

Zuber, M. T., D. E. Smith, F. G. Lemoine, and G. A. Neumann, 1994, The shape and internal structure of the Moon from the Clementine mission: Science, v. 266, p. 18391843, doi:10.1126/science.266.5192.1839. 
